\title{
Mobility of highly skilled individuals and local innovation activity
}

Citation for published version (APA):

Drivas, K., Economidou, C., Karamanis, D., \& Sanders, M. (2020). Mobility of highly skilled individuals and local innovation activity. Technological Forecasting and Social Change, 158, [120144].

https://doi.org/10.1016/j.techfore.2020.120144

Document status and date:

Published: 01/09/2020

DOI:

10.1016/j.techfore.2020.120144

Document Version:

Publisher's PDF, also known as Version of record

Document license:

Taverne

Please check the document version of this publication:

- A submitted manuscript is the version of the article upon submission and before peer-review. There can be important differences between the submitted version and the official published version of record.

People interested in the research are advised to contact the author for the final version of the publication, or visit the DOI to the publisher's website.

- The final author version and the galley proof are versions of the publication after peer review.

- The final published version features the final layout of the paper including the volume, issue and page numbers.

Link to publication

\footnotetext{
General rights rights.

- You may freely distribute the URL identifying the publication in the public portal. please follow below link for the End User Agreement:

www.umlib.nl/taverne-license

Take down policy

If you believe that this document breaches copyright please contact us at:

repository@maastrichtuniversity.nl

providing details and we will investigate your claim.
}

Copyright and moral rights for the publications made accessible in the public portal are retained by the authors and/or other copyright owners and it is a condition of accessing publications that users recognise and abide by the legal requirements associated with these

- Users may download and print one copy of any publication from the public portal for the purpose of private study or research.

- You may not further distribute the material or use it for any profit-making activity or commercial gain

If the publication is distributed under the terms of Article $25 \mathrm{fa}$ of the Dutch Copyright Act, indicated by the "Taverne" license above, 


\title{
Mobility of highly skilled individuals and local innovation activity ${ }^{\text {th }}$
}

\author{
Kyriakos Drivas $^{\mathrm{a}}$, Claire Economidou, ${ }^{* a}$, Dimitrios Karamanis ${ }^{\mathrm{a}}$, Mark Sanders ${ }^{\mathrm{b}}$ \\ ${ }^{a}$ Department of Economics, University of Piraeus, Piraeus 185 34, Greece \\ ${ }^{\mathrm{b}}$ Utrecht School of Economics, Utrecht University, 3512 BL, Utrecht, the Netherlands
}

A R T I C L E I N F O

\section{Keywords:}

Inventor mobility

Patents

Migration

Gravity

Proximity

JEL classification:

J61

O31

O33

O52

\begin{abstract}
A B S T R A C T
Mobilization of valuable resources, especially of talented individuals, figures prominently in firms' strategies and policy agendas. Thus far, there is a dearth of empirical evidence in the field. The contribution of this paper is two-pronged: first, to perform an integral evaluation of the different factors that shape the mobility of patent inventors -a specific class of highly skilled individuals, who are deeply involved in the production of innovation and are important vehicle of technological knowledge circulation- and second, to assess the effects of their mobility on local innovation activity. Employing detailed patent data to track their moves, we use a gravity model to examine whether geographic, technological, and cultural proximities between countries, among other factors, shape the flows of these talented individuals. Using the same framework of analysis, we also examine the mobility of non-inventor migrants. Our results show that although geographic distance still plays a role, inventor migrants are less geographically confined than non-inventor migrants. Countries' technology similarity is the main driver of inventor moves, whereas cultural -linguistic and religion- proximity matters more for non-inventor migrants. Finally, the knowledge and skills that move with the inventors have a positive effect on the production of new knowledge in the host country.
\end{abstract}

The success of any national or business model for competitiveness in the future will be placed less on capital and much more on talent. We could say that the world is moving from capitalism to "talentism". Klaus Schwab (Founder and Executive Chairman, World Economic Forum, 2011)

\section{Introduction}

Economic development is about mobilizing valuable resources to improve standards of living. Along with the typical resources, labor and capital, there is a growing recognition of the "intangible" resources such as technological knowledge, creativity, innovation, as important factors for economic growth. Behind all of these, there is "human talent" - the inner ability to create ideas and objects; some of them with high economic value.
The globalized process has mainly focused on the international mobility of capital, goods, (unskilled) labor, technology and to a lesser extent on the international mobility of high skilled, qualified, talented people. Recent reports have emphasized that the war for talent will be the major human resource issue in the upcoming years, when the people pipeline is the most crucial variable separating winners and losers in the marketplace. ${ }^{1}$ As population and workforce are trending down in most of mature economies the fight for talent will be even more intense. Companies may go to creative, perhaps even extreme, lengths to secure and retain talent and knowledge to stay competitive. Therefore, global mobility will play a key role in solving the labour availability.

Understanding and harnessing talent mobility is therefore more critical than ever. The mobility of highly skilled personnel in science, technology, engineering and mathematics (so-called STEM workers),

\footnotetext{
We are grateful to Alexandra Kechrinioti and Sofia Xesfingi for excellent research assistance. We also thank Miguel Amaral, Alexandros Bechlioulis, Kevin

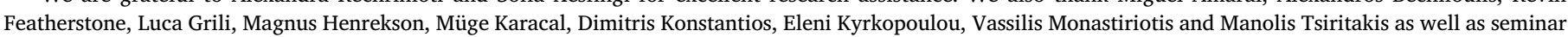

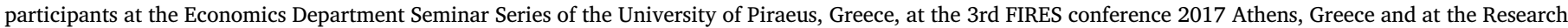

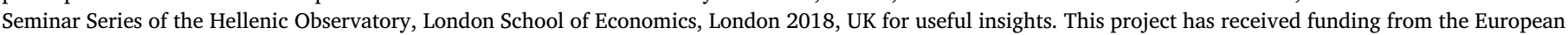

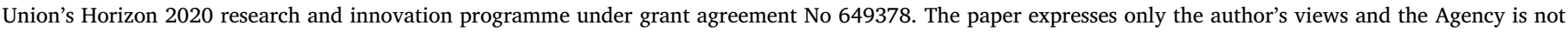

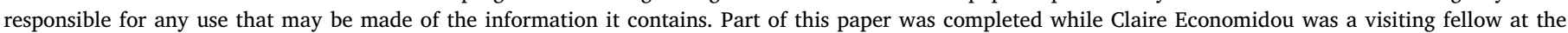
Hellenic Observatory, European Institute, London School of Economics, London WC2A 2AE. The usual disclaimer applies.

* Corresponding author.

E-mail addresses: drivas@unipi.gr (K. Drivas), economidou@unipi.gr (C. Economidou), karamanis@unipi.gr (D. Karamanis), m.sanders@use.nl (M. Sanders).

${ }^{1}$ See PWC report, "Talent Mobility 2020" available at https://www.pwc.com/gx/en/managing-tomorrows-people/future-of-work/pdf/talent-mobility-2020.pdf
} 
has figured prominently in many policy agendas. STEM skills are associated with advanced technical skills, which are seen as strong drivers of technology, knowledge-driven growth and productivity gains. ${ }^{2} \mathrm{Mi}$ grants represent a small proportion of total worldwide population of about 3\% (UN-DESA and OECD, 2013); however, the share of highskilled and particularly STEM migrants in some OECD countries has dramatically increased in recent years (Kerr et al., 2016). But despite the increasing international flows of STEM workers' and their recognized contribution in economic growth and convergence across countries (Eaton and Kortum, 1999), systematic empirical evidence on the impact of their migration on knowledge diffusion and (the performance of) regional innovation systems is still scarce.

The purpose of this paper is to study the mobility of highly skilled migrants and particularly of patent inventors. This specific class of workers belongs to the "upper-tail" of the human capital distribution and is more homogeneous than the tertiary educated or even STEM workers. ${ }^{3}$ There are two reasons why we focus on patent inventors: First, although inventors are just a small proportion of the skilled labour, they have a significant economic contribution; they are deeply involved in the production of innovation, which in turn is the main driver of economic growth (Romer, 1990). Second, they are also important vehicle of knowledge transmission - knowledge that cannot be codified and transmitted through other information channels requires 'knowledge-carriers' to physically move and create spillovers elsewhere (Breschi and Lissoni, 2009; Glaeser et al., 1995; Lucas, 1988).

First, we want to explore what moves the patent inventors. Inventor's mobility in our approach relates to the number of countries a patent inventor changes during lifetime every time she files for a new patent. To track inventor moves, we rely on a patent database that provides bilateral counts of "migrant inventors" for a large number of years as well as a considerable number of sending and receiving countries. By using a gravity model as our baseline, we analyze how geographic, technological, and cultural proximity between origin and host countries, along with other relevant country level factors, shape the flows of talented individuals. Our empirical gravity model is consistent with an underlying micro-founded random utility model (Bertoli and Moraga, 2015), while importantly also accounting for recent innovations in the empirical literature. We employ a zero-inflated negative binomial specification to account for the high proportion of zeroes in the dependent variable. Proximity has been explored in the past literature in a piecemeal approach (at least some types) in studying migration flows. In the present study, we perform a comprehensive analysis of different types of proximities, institutions and policies for all flows of inventors as well as accounting for the technological performance of their origin and destination country. Further, within the same framework and for comparison purposes, we also explore migration patterns of non-inventor flows.

Second, we assess whether local production of technological knowledge is strongly tied to the migration of talented patent inventors. As every inventor is a knowledge-carrier of her home-knowledge stock, we examine the inventor-weighted channel of external knowledge flows on a country's innovation production, proxied by the number of patents. Thus far, this channel has been understudied. A vast literature has focuses on the role of international trade (Coe and Helpman, 1995; Keller, 2002), patent citation (Branstetter, 2001; Jaffe et al., 1993; Peri, 2005), and foreign direct investment (Keller and Yeaple, 2009) as channels of knowledge transfer, but literature and systematic, global

\footnotetext{
${ }^{2}$ The mobility of highly skilled personnel - researchers, scientists, engineers has become one of the main pillars of the European Research Area launched by the Lisbon Agenda back in 2000.

${ }^{3}$ For example, tertiary graduate movers can be individuals with non-university tertiary degrees, undergraduate university degrees, postgraduate and doctorate degrees; however, these degrees may not always be fully comparable across different countries. More importantly, their contribution to innovation processes is only 'potential' and possibly delayed in time.
}

empirical evidence (especially beyond the US) on the migration of inventors as a channel is scarce.

Our paper thus relates and contributes to two important strands in the literature. Broadly, it associates to the literature on the determinants of international migration (Beine et al., 2011; Czaika and Parsons, 2015; Grogger and Hanson, 2011; Mayda, 2010; Ortega and Peri, 2013) and how they shape migrant flows. Our paper, however, speaks most directly to the strand of literature that specifically focuses on inventors' mobility (Miguélez and Moreno, 2014; Miguélez et al., 2010). Additionally, our paper makes an attempt to jointly study the drivers of both inventor and non-inventor flows within a common simple framework of analysis and for a large panel of countries. It also contributes to the debate on whether geographical distance still plays any role in explaining economic phenomena or technological advances have indeed overcome geography (Cairncross, 1997; Friedman, 2005; McCann, 2008; Rodríguez-Pose and Crescenzi, 2008).

Furthermore, we contribute to the literature of technological knowledge diffusion and particularly via the channel of the mobility of highly skilled individuals. ${ }^{4}$ This literature is thin and focuses mainly on the US. Contributions have explored the role of immigrant inventors in the process of technological development in the US from an historical perspective (Akcigit et al., 2017a; 2017b), in recent time periods (Hunt and GauthierLoiselle, 2010; Kerr and Lincoln, 2010) and the impacts of cross-state mobility of inventors (Drivas et al., 2016). Other studies have explored the role of knowledge networks through ethnic ties between the patent inventors diaspora in the US and innovation in their home countries (Agrawal et al., 2011; Breschi et al., 2017; Ganguli, 2015; Kerr, 2008; Kerr and Lincoln, 2010) with conclusions, especially about the effects of diasporas on knowledge absorption at home, to vary significantly. Even more scant is the evidence for any other country (for the UK; Crescenzi and Gagliardi (2015)) and even Europe (Miguélez and Moreno, 2013a; 2013b).

Our paper attempts to integrate two previously disconnected, yet important strands of research: the literature on the migration of inventor individuals and the literature documenting the role of migrant inventors in facilitating knowledge diffusion across borders around the world. ${ }^{5}$ Its contribution lies in performing an integral analysis of the factors that shape the mobility of highly talented individuals as well as the evaluation of their mobility on the innovation capabilities of a host economy for a large panel of countries. As an exercise, within the same framework we also compare the mobility of non-inventor flows.

We apply our modeling approach to 30 OECD countries over the period 2000-2012 with two key questions in mind: (i) What shapes the international mobility of inventors? (ii) What is the impact of inventor movers on innovation activity in the destination country?

Our evidence shows that proximity matters for migration. Gravity emerges everywhere; in the flows of inventor and non-inventor migrants; the former, however, stretch (about 1.5 times) farther in space than the latter. A first conclusion is therefore that geography has not been taken over by technological advancements and still shapes economic phenomena. This is evident by the significant drop in the mobility of inventors for distances large than $700 \mathrm{~km}$. Within a distance of $700 \mathrm{~km}$, there are four pairs of countries (Czech Republic and Germany, USA and Canada, Germany and Austria, and Germany and France) that exchange large flows of inventors. But technology certainly does matter. Technological proximity, and particularly the similarity in

\footnotetext{
${ }^{4}$ A parallel strand of research has also explored the mobility of researchers and their impact on regional innovation activity, documenting a positive and strong link. See Gagliardi (2015) for a recent review of this literature.

${ }^{5}$ We do not wish to position our paper in the more traditional "brain drain" literature. Although the knowledge migrants we study here represent an important conduit for knowledge transfer to the receiving region, ties with the home country remain strong and the numbers are too small to consider this a serious drain on the sending countries. Inventor mobility, in that sense, is not a zero sum game. The knowledge gained in the receiving place is not lost in the sending country and the latter's ability to innovate is not reduced.
} 
countries' technologies (i.e., patents in the same fields), is the main driver of inventor mobility - a finding that emerges particularly strong for inventors originating from the most innovative countries. For them, geographic closeness and cultural (i.e., religion and linguistic) similarity, though significant, play a less important role - particularly the latter. In contrast, cultural proximity matters most for non-inventor migrants. Attractive country features for an inventor to re-locate herself are the quality of institutions and the job opportunities at the destination country as well as the trade linkages between origin and host country. Finally, we find that external knowledge, accessible to a country via inventors' moves, contributes, on average, about 0.23 per cent to the production of new knowledge in the host country, especially when the incoming inventors originate from the most innovation efficient countries. We, thus, find significant evidence of knowledge transfer from inventor migration.

Our findings are therefore relevant also for the growth literature. Theoretical studies (Grossman and Helpman, 1991; Rivera-Batiz and Romer, 1991) have emphasized the important consequences of disembodied and embodied knowledge flows for growth. Our study shows such theoretical notions find empirical support by analyzing knowledge diffusion via the channel of highly skilled inventors' mobility and its impact on local innovation activity. We find that knowledge flows are relevant to a country's innovation production, as external knowledge accessed through the inflow of inventors has a positive effect, confirming thus the importance of knowledge flows embodied in people for technology transfer and economic growth.

Our results further highlight the importance of policies and factors conductive to attract patent inventors. High quality, efficient and effective regulatory environment - mainly related to competition, taxation, finance, investment, and doing businesses - and job opportunities and synergies at the destination country as well as intense trade activity are found to be important attractors for talented individuals. To the extent that external knowledge is relevant for local innovation activity, we argue that immigration policies should be welcoming to skilled and innovative individuals; The general stance on migration and foreigners may well also affect the inflow of talented inventors. Technological proximity is more important for them, but cultural proximity helps and a welcoming environment may well be an important factor in future migration flows. A message particularly relevant for countries with ageing and shrinking populations that are thinking of imposing harder restrictions on the migration of ordinary people.

The remainder of the paper proceeds as follows. Section 2 introduces the framework for analyzing migration flows and the estimation technique. Section 3 discusses the data. Section 4 presents the results. Finally, Section 5 summarizes the findings and concludes.

\section{A framework of analysis}

\subsection{Modeling migration flows}

The decision of inventors to move is influenced by the comparison between expected utilities of the origin and destination locations. Migrating across countries has costs, monetary and non-monetary. The geographical separation between countries proxies some of the distance-related costs such as the sunk cost of re-location that are difficult to measure empirically. Technological distance also proxies for costs of adjusting in different (or similar) technological environments. Similarly, differences in culture, language and religion, bring additional challenges and costs for the migrants. Other amenities of the host and origin countries can also shape the migrant's expected utility. ${ }^{6}$ An inventor, therefore, will decide to move to another country, if the

\footnotetext{
${ }^{6}$ There are myriad non-economic factors that highly-skilled migrants likely value in their decision to move, such as the standard of living, the quality of schools, health services, infrastructure, presence of a well-established professional network among others (Papademetriou and Sumption, 2013).
}

expected utility of the destination country is greater than the expected utility of the origin country.

We use a gravity-like equation to model migration flows, as conventionally has been proposed in the literature. Gravity regressions consist a robust formulation in analyzing trade flows primarily because they can be derived from an equilibrium model with optimizing firms (Anderson and van Wincoop, 2003; Helpman et al., 2008). Interestingly, one of the first applications employing geographic distance, a core feature of gravity, was to describe migration patterns (Ravenstein, 1889). Only much later, Tinbergen (1962) employed gravity to examine trade flows. Unlike trade which encompasses two choices, exporting in a destination and how much to export, migration encompasses only one choice: for an individual to migrate to a destination from a set of alternative destinations. The pioneering work by McFadden (1974) that modeled choices through a multinomial logit provided the insights to model migration flows. Beine et al. (2011) and Grogger and Hanson (2011) built a gravity model between countries basing the migration behavior of individuals between countries as a discrete choice. With these insights the gravity model aggregates individual migration behavior at the country level. The micro-founded gravity model of international migration has become the theoretical workhorse on which the majority of studies that examine the determinants of migrants' location decision are now based (Beine et al., 2011; Grogger and Hanson, 2011; Mayda, 2010; Ortega and Peri, 2013).

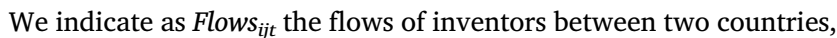
$i$ (destination) and $j$ (origin) at year $t$. Therefore, for any country-pair $i$ and $j$, we model the mobility of inventors to depend on geographic, technological, and cultural closeness, along with county-level factors, as follows:

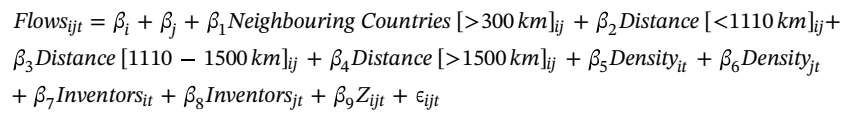

where $\beta_{j}$ and $\beta_{i}$ are origin and destination, respectively, country fixed effects; Neighbouring Countries [ $>300 \mathrm{~km}$ ] takes the value of 1 for flows exchanged between countries that share a common border and their geographical centers are located in a distance more than $300 \mathrm{~km}$, and 0 otherwise; the generic term Distance [ ] denotes various distance classes and take the value of 1 for flows exchanged between countries $i$ and $j$ that are located within a certain distance class, and 0 otherwise; Density is population over country's area; Inventors is the number of total inventors within a country; $Z$ is a control vector that contains technological, cultural and other country level factors; and, finally, $\epsilon$ is an iid error term.

The coefficients $\beta_{1}$ to $\beta_{4}$ provide a characterization of how geographic factors shape inventor flows across countries. By model construction, each geographic coefficient captures the difference between knowledge flows diffused in geographic space to knowledge flows diffused within an area of $300 \mathrm{~km}$. $^{7}$ We use the neighboring area of a country as a benchmark to perform comparisons of inventor mobility flows across various distance classes. We opted for this distance taxonomy for the following reason: The longest distance between two neighboring countries in our sample is approximately $1110 \mathrm{~km}$ and this is the distance between the most populated cities of France and Italy, as the crow flies. There are also neighboring countries that their geographic centers are located in less than $1110 \mathrm{~km}$; for instance Belgium (Brussels) and the Netherlands (Amsterdam) are $174 \mathrm{~km}$ apart (as the crow flies). Therefore, neighboring countries are broken down into two groups: Neighboring Countries $[<300 \mathrm{~km}$ ] and Neighboring Countries [

\footnotetext{
${ }^{7}$ As we do not have data on the mobility of inventors within a country, we use as a benchmark the $300 \mathrm{~km}$ 'neighboring' area of a country based on our sample. See Data Section for country incluson.
} 
$>300 \mathrm{~km}$ ], which take the value of 1 for flows exchanged between countries that do share a common border but their geographical centers are located in a distance less (more) than $300 \mathrm{~km}$, and 0 otherwise. The cut-off value of $300 \mathrm{~km}$ was chosen simply because it gives equal number of neighboring countries within these two distance classes. We proceed till we exhaust the distance between the two farthest located countries in our sample. ${ }^{8}$ The proposed classification, Distance [ $<1110 \mathrm{~km}]$, Distance $[1110-1500 \mathrm{~km}]$, and Distance $[>1500 \mathrm{~km}]$, allocates about equal number of countries in each distance class, which are not neighbors, meanwhile keeping the number of classes as low as possible. ${ }^{9}$ Our benchmark distance class is the Neighboring Countries [ $<300 \mathrm{~km}$ ], and therefore not included in the model. All geographic coefficients, consequently, will be compared to that benchmark area. For example, $\beta_{1}$, the coefficient of Neighboring Countries [ $>300 \mathrm{~km}$ ], captures the effect of geographic nearness of countries that share common borders but are located in more than $300 \mathrm{~km}$ away, compared to flows exchanged in less than $300 \mathrm{~km}$. Each one of the coefficients of the rest of the distance dummies, examines whether countries, located at a specific distance class exchange less (or more) flows in comparison to flows that take place in an area of less than $300 \mathrm{~km}$. One would expect that increasing geographic distance would reduce exchange among countries, signaling that migration flows are bounded in space and characterized by spatial declining effect. ${ }^{10}$

As in any typical gravity model, we include the area and population or equivalently the density, Density (= Population/Area), of a country to control for the spatial distribution of economic activity (Frankel and Romer, 1999). Glaeser et al. (1995) argue that low density areas are highly attractive to migrant flows. One should expect, then, a negative influence of density on inventors inflows. However, it could be also argued that dense urban areas may have a larger supply of producer and consumer amenities (Perugini and Signorelli, 2010), so a positive effect of density might be also observed for the destination country and negative for the origin. Further, we also include the total number of inventors, Inventors, to proxy for the size of the labor market for inventors and to capture the job opportunities and synergies. We therefore expect a positive sign for inventors' coefficient for the destination and a negative (or unambiguous) for the origin country.

The $Z$-set includes variables that relate to the technological proximity and cultural similarity between countries as well as institutions and policies that could be attractive factors in both countries. Controlling for the geographic distance, countries may exchange migration flows with each other simply because they have, for instance, similar technological efforts and/or technology specialization of production structures or because they share common culture and roots or because some countries have very attractive conditions and policies. Not accounting for such differences may lead to an overestimation of the geography effect.

Therefore, we also consider, along with the geographic proximity, the effect of the technological closeness between two countries, which is proxied by two indices, technological effort and technological specialization of production proximity.

\footnotetext{
${ }^{8}$ The longest pair-country distance in our sample is the distance between Portugal and Japan: about $11,200 \mathrm{~km}$ and the shortest pair-country distance is between Slovakia and Austria: about $60 \mathrm{~km}$.

${ }^{9}$ Alternative division of geographic space is not expected to modify results in any significant way. Continuous definitions of distance (e.g. polynomials) are not considered in this paper as we would like to stay close to the relevant literature (Mancusi, 2008; Peri, 2005), and further do not expect great loss of information.

${ }^{10}$ The localization of knowledge flows - exemplified by a variety of mechanisms such as citation, trade, and inventor flows - has been considerably tested in the knowledge spillover literature, which has unanimously documented the geographic confinement of knowledge diffusion (Alcacer and Gittelman, 2006; Belenzon and Schankerman, 2013; Jaffe et al., 1993; Peri, 2005; Thompson, 2006).
}

More specifically, distance in the technological effort, TechEffortDistance, between two countries $i$ and $j$ for a given year, $t$, is proxied as ${ }^{11}$ :

$$
\text { TechEffortDistance }=\ln \frac{R \& D_{i}}{\text { Scientists }}-\ln \frac{R \& D_{j}}{\text { Scientists }}
$$

One would expect that the larger the technological distance, the bigger the inventor inflows, as high technological active places tend to be more attractive for inventors and generate more economic growth (Lucas, 2009; Romer, 1986; 1989).

The similarity in the technological specialization of production sectors, TechSpecialisationSimilarity, between two countries $i$ and $j$ for a given year $t$ is proxied by the (uncentered) correlation of their patent profiles and calculated as: ${ }^{12}$

TechSpecializationSimilarity $=\frac{s h_{i}{ }^{\prime} s h_{j}}{\sqrt{\sum_{s=1}^{8} s h_{i s}^{2} \sum_{s=1}^{8} s h_{j s}^{2}}}$ where, sh are shares of patents issued in a technology field (out of eight, in total, fields) in countries $i$ and $j$.

The constructed index ranges from zero (minimum similarity), which implies that the production structures are orthogonal, to one (maximum similarity), which denotes identical sectoral structure (i.e., patenting in exactly the same sectors) in two countries. Researchers are expected to benefit more from other researchers who work in the same or related sectors (Bode, 2004). Consequently, one expects to find larger inventor flows between countries specialized in similar than in dissimilar sectors.

Another, less explored, proximity that could shape inventor flows is cultural closeness between countries. Culture is history, religion, language, attitudes, values, beliefs and assumptions learned in early childhood that distinguish one group of individuals from another that can be critical also to innovation attitudes (Beck and Moore, 1985). The dominant view in the literature is that national culture has a strong impact on organizational culture (Hofstede, 1980; 2001). Certain cultural norms and behaviors for instance, trust and openness, awards and rewards, autonomy and flexibility may facilitate an innovative climate in organizations and help the organization to innovate more quickly, be agile in changing times, and get products to market faster than competition, while other aspects can impede innovation process. ${ }^{13}$ Individuals whose languages and religions share common roots may also share similar cultural backgrounds. Therefore, we introduce culture

\footnotetext{
${ }^{11}$ The level of technological capability of a region is often proxied in the literature (Peri, 2005) by the level of R\&D activity and human capital (number of researchers). According to innovation-driven models of growth (Aghion and Howitt, 1998; Grossman and Helpman, 1991), R\&D stimulates innovation and facilitates the imitation of others' discoveries. Apart from contributing directly to invention, human capital also accounts for aspects of innovation not captured by the R\&D sector, including 'learning-by-doing' and 'on-the-job-training' (Redding, 1996; Romer, 1989).

${ }^{12}$ Technological specialization proximity between two countries is measured as in Jaffe (1986). We first classify each patent, according to their primary international patent classification, in one of 8 technology fields (Human Necessities; Performing Operations, Transporting; Chemistry, Metallurgy; Textiles, Paper; Fixed Constructions; Mechanical Engineering, Lighting, Heating, Weapons, Blasting; Physics; and Electricity). Then, for each country, we create a patent profile by taking the vector of shares of patents issued in technology field, $S h_{i}=\left(s h_{i 1}, s h_{i 2}, \ldots, s h_{i 8}\right)$, for a given year.

${ }^{13}$ In his seminal study, Hofstede (1980) and subsequent studies (Efrat, 2014; Herbig and Dunphy, 1998; Jones and Davis, 2000) examine the effect of four dimensions of culture, i.e, power distance (acceptance of social stratification), individualism versus collectivism, masculinity, and uncertainty avoidance (the degree to which the members of a society feel uncomfortable with uncertainty and ambiguity) on innovation activity. For example, the presence and level of social or organizational hierarchy, centralized power, formal vertical communication flows, top down control, formal rules and procedures, and resistance to change impede innovation. Further, individualistic societies value freedom more than collectivist societies and freedom is necessary for creativity. Characteristics associated with strong uncertainty avoidance, such as the need for consensus, formal rules and procedures, tend to inhibit innovation capabilities.
} 
proximity in our model via language and religion similarity.

To construct a language similarity index, Linguistic Similarity, we assign each language of every country in our sample to one of the six dominant Indo-European subfamilies, i.e., Germanic, Romance, Slavic, Baltic, Celtic and Greek, and one non Indo-European, the Uralic - the latter, includes Estonian, Finnish, and Hungarian. ${ }^{14}$ The index gets the value of 1 if the country pair belongs in the same subfamily, and zero otherwise.

To construct an index of religion similarity, ReligionSimilarity, we follow Miguélez (2016) and proxy religion similarity for each country pair, $i, j$ and for a given year $t$, with an index built as follows:

$$
\begin{aligned}
& \text { ReligionSimilarity }_{i j}=\left(\% \text { muslim }_{i} * \% \text { muslim }_{j}\right)+\left(\% \text { catholic }_{i} * \% \text { catholic }_{j}\right) \\
& +\left(\% \text { orthodox }_{i} * \% \text { orthodox }_{j}\right) \\
& +\left(\% \text { protestant }_{i} * \% \text { protestant }_{j}\right) \\
& +\left(\% \text { hinduism }_{i} * \% \text { hinduism }_{j}\right) \\
& +\left(\% \text { buddhist } t_{i}^{*} \% \text { buddhist }_{j}\right) \\
& +\left(\% \text { eastern }_{i} * \% \text { eastern }_{j}\right) \\
& +\left(\% \text { judaism }{ }_{i}^{\left.* \% j u d a i s m_{j}\right)}\right.
\end{aligned}
$$

The index ranges from 0 (no believers in common) to 1 .

Culture similarities tend to facilitate the formation of trust and mutual understanding of individuals, smooth out communication problems, ease the screening of potential partners, help the managing and administration of a common project and share similar attitudes towards approaching innovation. Inventors can operate better in environments which are familiar in the way innovation is managed and supported. Therefore, we expect a positive association between cultural closeness between countries and inventor mobility.

Additionally, we include country level factors that mainly relate to institutional environment and quality that affect the innovation capabilities of a country and therefore the flows of inventors. Institutions are important conditions for financial development, which in turn associates with more innovation capabilities (Hsu et al., 2014), and for economic growth (Levine, 2004); they are also exogenous and therefore alleviate possible concerns of causality issues. ${ }^{15}$ The literature argues that the levels and modes of innovation as well as the position of a place with respect to the technological frontier are shaped by the surrounding institutions (Busenitz et al., 2000; Edquist et al., 2001; Licht and Siegel, 2006). Formal and informal government institutions, rules, regulations, laws, contracts, and policies affect economic incentives and thus the incentives to invest in technology, physical and human capital. They are also responsible for regulating learning processes, supporting the formation of mutual trust, facilitating the transmission of knowledge between innovation agents (Acemoglu et al., 2005; Caselli and Coleman, 2001) and fostering economic growth. ${ }^{16}$ We include the

\footnotetext{
${ }^{14}$ Germanic languages are spoken in central and northern Europe and include Danish, Dutch, English, German, and Swedish. Romance languages are spoken in western, southern European regions; they include French, Italian, Portuguese, Romanian, and Spanish. The Slavic languages are to be found in the central Europe and the Balkans in southern Europe. They include Bulgarian, Croatian, Czech, Polish, Slovak, and Slovene. The Baltic languages are Latvian and Lithuanian. The Celtic languages include Irish. Finally, the Greek language which is spoken in Greece and Cyprus. Outside the Indo-European family, Estonian, Finnish and Hungarian are Uralic languages. For further details, see www.ethnologue.com.

${ }^{15}$ Institutions have been used as proxies of economic and financial activity. Therefore, we refrain from using measures of output (for instance, gross domestic product) or financial development as these variables are endogenous and reverse causality could be a serious issue.

${ }^{16}$ Empirical evidence corroborates with the theoretical considerations. For instance, the study of Rodríguez-Pose and Cataldo (2014) finds that ineffective and corrupt governments represent a fundamental barrier for the innovative capacity and strongly undermining any potential effect of any measure aimed at promoting greater innovation.
}

quality of regulations as a proxy of the institutional environment, which refers to regulations related to finance and do businesses (regulatory burdens, competition policies, tax inconsistencies and tax discriminations, easiness of starting a business, financial and investment freedom).

We also include knowledge institutions proxied by the level and quality of human capital. Human capital is an input in the innovation process and therefore serves as a complement to technology. Higher levels of human capital lead to generation or diffusion of new technologies or to a more efficient adoption of a given technology (Benhabib and Spiegel, 1994; Romer, 1990). Further, policies related to higher (tertiary) education could also be relevant for influencing the direction of inventor flows as higher level of education leads to more economic growth (Aghion et al., 2009).

We further consider labor institutions and regulations but only for a subset of countries as data are not always available. Labor regulations increase job security and greater enforceability of job contracts and, therefore, could increase worker investment in innovative activity; however, strict labor legislation also increases firms' adjustment costs, which may lead to underinvestment in activities that are likely to require adjustment, including technologically advanced innovation (Griffith and Macartney, 2014).

Finally, we include the trade linkages between countries. The reason is that trade acts as conduit of information and may also foster technological partnerships (Drivas et al., 2016). Particularly, imports of foreign capital and intermediate goods allow a recipient country to learn from the R\&D-, or 'technology'-content embodied in the traded good and consequently, merchandise trade serves as an important vehicle of knowledge exchange between trading partners (Caselli and Wilson, 2004; Eaton and Kortum, 2001; Grossman and Helpman, 1991; Keller, 2002).

\subsection{Estimation approach}

The first step of our analysis consists of estimating the coefficients of Eq. (1). As the response variable is a discrete one with distribution that places the probability mass at non-negative integer values, count data models are suitable in this framework (Cameron and Trivedi, 2013). ${ }^{17}$

The most basic type of count data model is derived from the Poisson distribution and one can use a Poisson pseudo-maximum likelihood method of estimation. However, the Poisson distribution assumes equidispersion; that is, the conditional variance equals the conditional mean. In the case of overdispersion, which often appears due to the presence of individual unobserved heterogeneity in the data generating process, the Poisson regression may lead to consistent, but inefficient estimates (Burger et al., 2009) with standard errors biased downward (Cameron and Trivedi, 2013) and, therefore, a negative binomial (NB) estimation technique is more appropriate.

Although negative binomial (and count data, in general) models are explicitly designed to deal with the presence of zeros in the dependent variable, these zeros may come from different data generating processes. In our context, the level of individual flows between countries is frequently zero. Small countries may not show mobility of individuals with all possible partners or because statistical offices do not report such flows below a certain threshold. The zero-inflated negative binomial (ZINB) model (Greene, 1994; Lambert, 1992) applied to negative binomial models allows to better estimate a large amount of zero flows since it considers the existence of two groups within the population: the first having strictly zero counts and the second having a non-zero probability of having bilateral flows bigger than zero.

Consequently, our estimation approach, the ZINB model, may be

\footnotetext{
${ }^{17}$ The logarithmic transformation of the data and OLS estimation techniques, often applied in gravity models, would lead to inconsistent estimates, as for some pairs of countries there is no exchange of inventors, making the logarithmic transformation of these observations impossible.
} 
viewed as a two-part extension, in which the distribution of the outcome is approximated by mixing two component distributions: the zeroinflated part that consists of a model to determine the probability of whether a particular origin-destination flow will be zero or positive as a function of certain characteristics - a set of covariates that predict the probability of belonging to the strictly-zero group ${ }^{18}$; and second the standard negative binomial gravity model to estimate the relationship between the mobility of flows and explanatory variables for each flow that has a non- zero probability. ${ }^{19}$

We perform a number of tests to decide on the appropriateness of our estimation method. We first examine whether overdispersion is present and consequently negative binomial is preferred to poisson and do a likelihood ratio (LR) test. Then, we assess whether the zero-inflated negative binomial is preferred to its poisson counterpart with the use of the Vuong statistic (Vuong, 1989).

The second step of our analysis is to estimate a knowledge function. In doing so, we first estimate Eq. (1), using zero-inflated negative binomial estimation techniques as explained above, and calculate the fitted values. Then, we use these values as weights for the external accessible technological knowledge that comes from other countries via the moves of inventors, and assess the contribution of foreign knowledge on a country's innovation activity.

\section{Data description and analysis}

Our empirical analysis is based on 30 technologically advanced countries for the period 2000 to $2012 .{ }^{20}$ Data are obtained from a range of sources.

Information on inventors' mobility (Flows), defined as the number of countries a patent inventor changes during lifetime every time she files for a new patent, is obtained from the World Intellectual Property Organization (WIPO) Database, which is publicly available and described in detail by Miguélez and Fink (2013). ${ }^{21}$ An occurrence of inventor mobility is counted only if an inventor files for a patent either under a different owner (firm) or the same owner but in different country. We construct inventors' mobility flows by counting the number of occurrences in every year. ${ }^{22}$ From the WIPO dataset we also derive information about the total number of inventors per country.

Information on migrant flows (Flows ${ }_{n i}$ ), defined as the number of countries a migrant changes during her lifetime, is obtained from the Organization of Economic Cooperation and Development (OECD), International Migration Database. ${ }^{23}$ Data, however, we do not provide any further information on the composition (engineers, doctors, scientists, etc) of these flows.

\footnotetext{
${ }^{18}$ Some factors may be more important in determining the increased utility because of the decision to move rather than the potential volume of bilateral flows. In principle, there is no formal restriction to including the same regressors both in the binary and the negative binomial process, aside from possible theoretical considerations.

${ }^{19}$ Among others, Xiong and Beghin (2011) and Philippidis et al. (2013) have applied zero-inflated count models for the analysis of international trade and Miguélez and Moreno (2014) for bilateral inventor flows.

${ }^{20}$ These countries account for about $83 \%$ of the world's R\&D expenditure and $98 \%$ of its patenting (OECD, 2004). Countries in our sample are presented in Table A1 in the Appendix.

${ }^{21}$ The WIPO maps migratory patterns of inventors extracted from information contained in patent applications filed under the Patent Cooperation Treaty (PCT). The database contains bilateral counts of "migrant inventors" for a large number of years as well as a considerable number of "sending" and "receiving" countries. Information on the data is provided at http://www.wipo.int/ publications/en/series/index.jsp?id $=138 \&$ sort $=$ code.

${ }^{22}$ Mobility of inventors is measured in our paper through patent data. Clearly, our proposed measure does not include inventors that move without patenting.

${ }^{23}$ Only 22 (out of 30 ) countries have full information on bilateral migration flows for the period under investigation.
}

Geographical closeness (Neighbouring Countries [ > 300Km] and various distance classes (of non-neighboring countries) denoted by Distance [ ]) is measured by the geographic distance (in kilometres) between two countries' geographical centers as the crow flies. This information is obtained from the Mayer and Zignago (2011). ${ }^{24}$ Data on the geographical area and population to construct a country's density (Density) - measured in millions of people per hundred thousands square kilometres - are obtained from the World Bank, World Development Indicators (WDI).

Information on R\&D expenditure and number of scientists (science, engineering, and health researchers) to construct technological closeness (TechEffortDistance) comes from the World Bank Science and Engineering State Profiles. Patents' primary International Patent Classification (IPC) as well as patent file data are extracted from the OECD patent database, Science, Technology and Patents. ${ }^{25}$ To construct technological effort distance (TechEffortDistance) we allocate patents into eight technological fields based on the IPC system.

We derive information from the Ethnologue Project to construct the linguistic similarity (LinguisticSimilarity) between two countries. ${ }^{26}$ The Central Intelligence Agency (CIA) World Factbook Dataset provides the percentage of population adhering to one of eight major religions in order to construct the religion similarity (ReligionSimilarity). ${ }^{27}$

Data on a country's institutions (Institutions), proxied by the 'regulatory quality', are obtained from the World Bank, Worldwide Governance Indicators (WGI). The regulatory quality index captures perceptions of the ability of the government to formulate and implement sound policies and regulations that permit and promote private sector development. ${ }^{28}$ Information on the strictness of employment protection legislation (EPL) for overall, regular, and temporary employment comes from the OECD Employment Database. ${ }^{29}$ We use data on public spending on tertiary education (\% GDP) obtained from the World Bank, World Development Indicators to proxy governments' knowledge-supporting policies for human capital (HumanCapital). ${ }^{30}$ Finally, bilateral merchandise trade flows (Trade) are derived from the OECD Structural Analysis (STAN) Bilateral Trade Database.

For the second stage of our analysis, we need information on a country's innovation activity. Commonly in the literature, innovation activity is proxied by patents. Information on the numbers of patent applications (Patents) per country is derived from the WIPO database, WIPO Patent Report: Statistics on Worldwide Patent Activity.

Table A2 in the Appendix provides summary statistics of the variables. For every pair of countries, in a given year, there are, on average, 18 occurrences of inventors' mobility compared to almost 2082 moves of non-inventor migrants. On average, there are 9300 inventors in each country. Each pair of countries is, on average, 5.5\% likely to be neighboring with each other and to be located in more than $300 \mathrm{~km}$

\footnotetext{
${ }^{24}$ See "Notes on CEPII's distances measures: The GeoDist database," CEPII Working Paper 2011-25, December 2011.

${ }^{25}$ Available at https://stats.oecd.org/Index.aspx?DataSetCode=PATS_IPC.

${ }^{26}$ Available at www.ethnologue.com.

${ }^{27}$ Available at https://www.cia.gov/library/publications/the-worldfactbook/.

${ }^{28}$ Regulatory quality index is a synthesis of policies and regulations related to finance and do businesses, namely regulatory burdens, competition policies, tax inconsistencies and tax discriminations, easiness of starting a business, financial and investment freedom among others.

${ }^{29}$ The employment protection legislation measures the procedures and costs involved in dismissing individuals or groups of workers and the procedures involved in hiring workers on fixed-term or temporary work agency contracts. EPL refers a dimension of a complex set of factors that influence labour market flexibility. The EPL index ranges from 0 (least restrictive) to 6 (most restrictive).

${ }^{30}$ For robustness analysis and for a limited number of countries in our sample due to data limitations, we use the share of population in mathematics and computing, engineering at the manufacturing sector (STEM) from the Eurostat and human resources devoted in science and technology (HRST) as a share of the active population in the age group 25-64 from the OECD.
} 


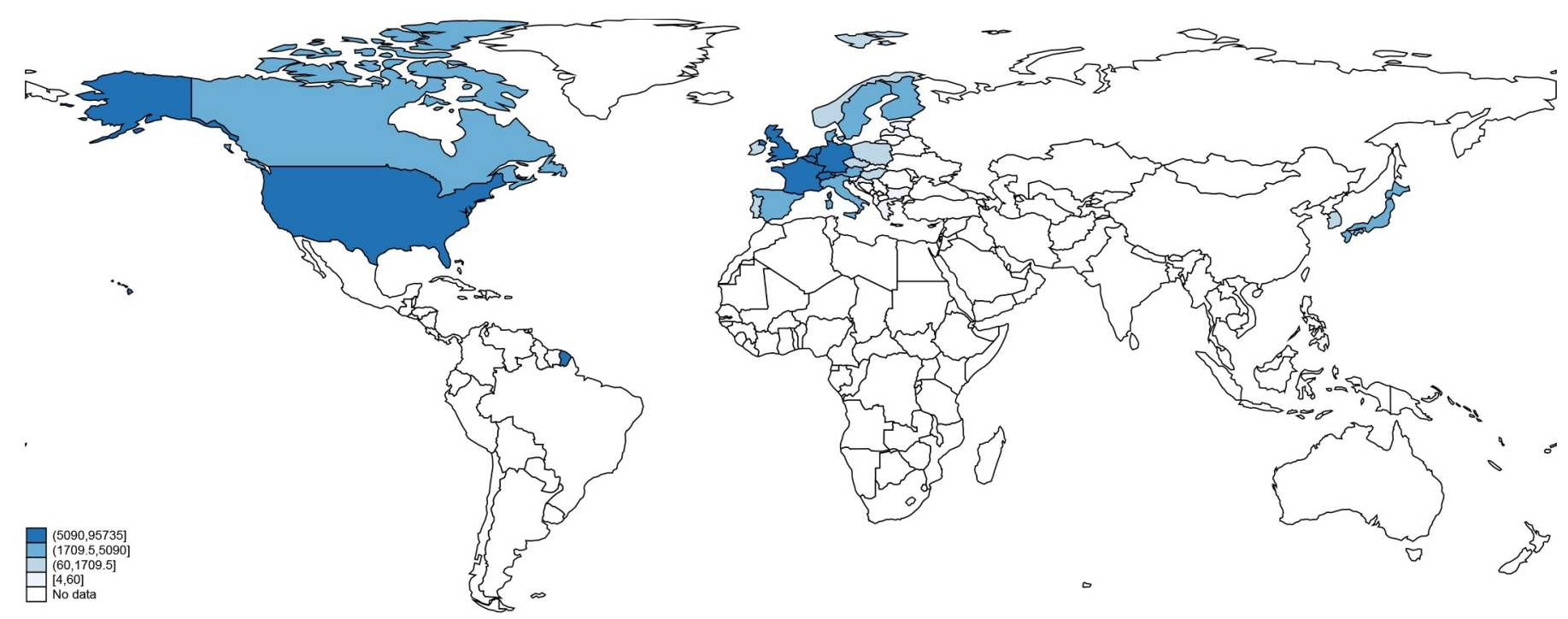

Fig. 1. Inventor inflows in technologically advanced countries, 2000-2012.

away from each other, $22.5 \%$ within a distance of 300 to $1110 \mathrm{~km}, 16 \%$ in a distance of 1110 to $1500 \mathrm{~km}$, and $5.4 \%$ further than $1500 \mathrm{~km}$. The average country's density is 13.6 million people per hundred thousands square $\mathrm{km}$. In terms of technological effort, countries, on average, appear to be less distant than the maximum potential distance, but not quite close in terms of technological specialization in their productions. On average, for a given pair of countries there are large cultural, in terms language and religion, and institutional differences. Further, countries spend on average $1.3 \%$ of their GDP on tertiary education and file for 105 patents per year. Finally, the trade intensity between any two countries is about $4 \%$ of their total trade. A correlation matrix for all variables in our analysis is provided in Table A3 in the Appendix.

Fig. 1, below, shows the inventor inflows for the period 2000-2012.

Intense inventor flows (dark blue) are concentrated in few OECD countries; US, Germany, France and the UK attract large flows of inventors, whereas Greece, Portugal and Spain the least.

The country pairs with the highest exchange of inventors across all countries and over our time span are shown in Fig. 2.

There are 68 (out of 870 ) country pairs that inventors' mobility between them is very high; on average, more than 70 occurrences per year - these occurrences lie at the top $5 \%$ of the inventor flows distribution. This indicates that high inventors' mobility is observed across very few countries in the OECD group. As Table A4 in the Appendix shows, large inventor flows are observed from Canada to the US $(21,837$ occurrences), UK to US $(17,424)$, Germany to Switzerland (9719), Korea to the US (8617), and Germany to the US (1204). In Europe, the highest inventor flows are observed from France to Switzerland (3273), Austria to Germany (3147), France to Germany (3039), and Germany to the Netherlands (2498). Overall, countries that exhibit the highest inflows of inventors are also the ones with the highest outflows. Inventors, and subsequently the knowledge they carry, move across a small number of developed countries. Finally, a consistent finding that emerges is that countries, which are top ranked in patents, and R\&D spending are also the ones that have high inventor mobility, with the US to be by far an outstanding attractor of inventors.

\section{Empirical results}

This section presents our results. First, we examine the effect of various types of proximities and other institutional mainly factors in shaping international flows of inventors, and, second, whether these flows, and the knowledge they carry, have an impact on countries' innovation activity.

\subsection{What shapes the moves of highly skilled migrants?}

Table 1 reports zero-inflated negative binomial (zinb) estimates of inventor migration flows of Eq. (1). We begin by reporting in column (1) gravity model estimates, where the bilateral flows of inventors are shaped only by geographic, technological, cultural proximity between countries and other factors, all included in the $Z$ set. The equivalent logit estimates are also reported in the same column. The following columns explore whether the importance of the aforementioned proximities and institutional factors vary depending on the technological performance of inventors' country of origin. Accordingly, columns (2) and (3) report estimates of inventor flows only from the top five most innovative to less innovative countries, and to all countries, respectively, while columns (4) and (5) report estimates of inventor flows from less innovative countries to top five most innovative, and to all countries in our sample, respectively. ${ }^{31}$

Before embarking on analyzing our results, we run some tests to ensure that the zinb model is the most appropriate one. For this reason, we perform and report at the bottom of each regression in Table 1 some statistics. First, we test whether there is overdispresion in our sample; in presence of no overdispresion (i.e., mean is equal to variance) poisson estimation is the appropriate method. The likelihood ratio (LR) test rejected the null hypothesis of no overdispersion in all specifications. Next, we test between negative binomial and zero-inflated negative binomial models. The Vuong test performed is in favor of the null hypothesis of zero-inflated model to accommodate our estimations to the excess of zeros. One would interpret the coefficients of a zero-inflated negative binomial model as in a standard negative binomial regression all coefficients can be interpreted as elasticities once they are exponentiated. ${ }^{32}$ The interpretation of the logit estimates is somewhat different: if a logit regressor was to change by one point, while holding all other variables in the logit model constant the odds of belonging to the 'strictly zero group', i.e., the zero-bilateral mobility in our case, would change by a factor equal to the exponentiated corresponding coefficient.

The first column in Table 1 presents estimates of various types of

\footnotetext{
${ }^{31}$ To economize in space, the accompanied logit estimates of columns (2)-(5) are not reported, but they are available upon request.

${ }^{32}$ To convert each value to percentage change, we use the exponential formula, $e^{\beta}$. In case regressors are already in logarithmic terms, their coefficients are already elasticities. See Cameron and Trivedi (2013, p. 95).
} 


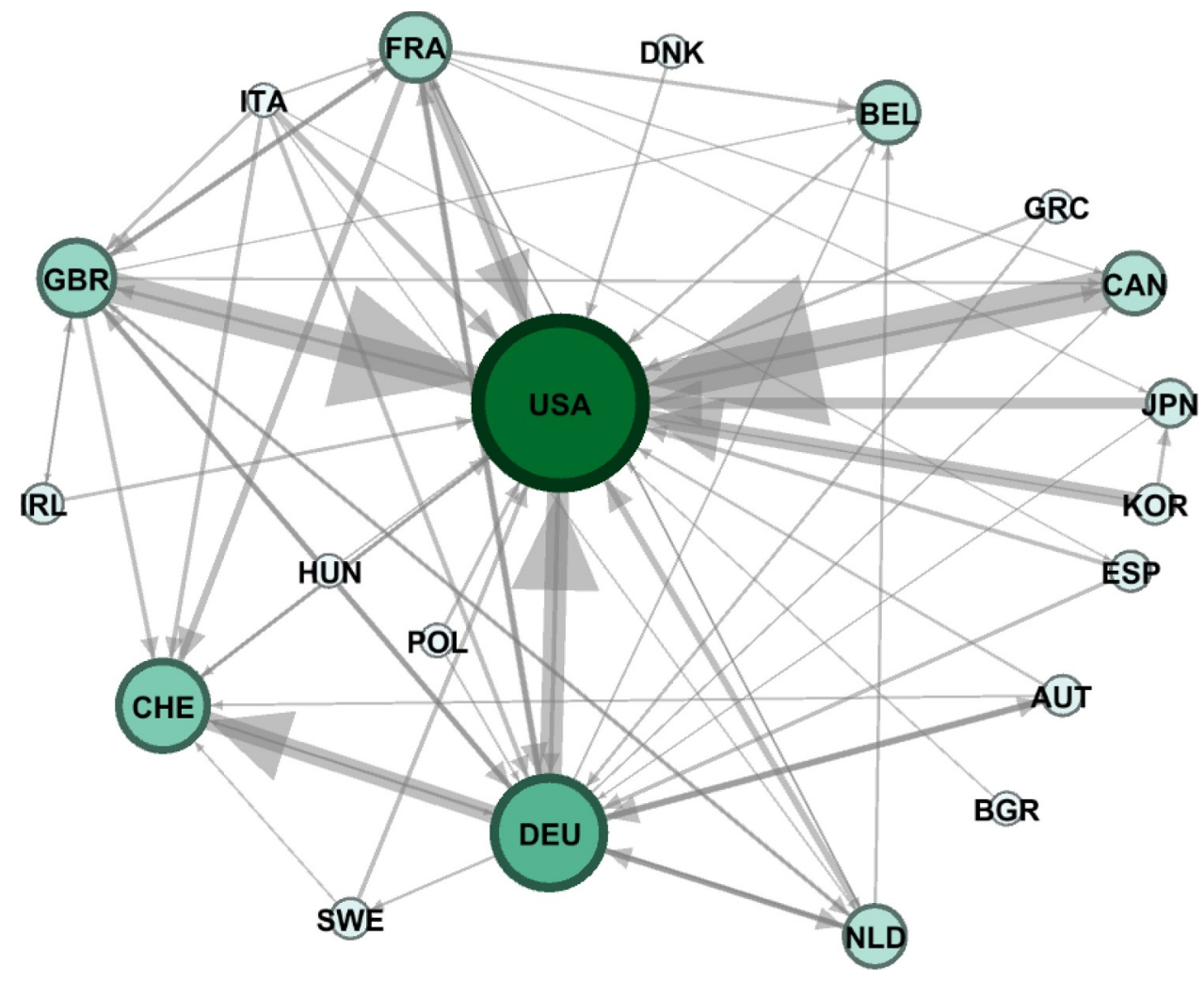

Fig. 2. Top 5\% inventor flows across technologically advanced countries, 2000-2012.

proximities. For robustness, Table A5 in the Appendix builds up the various proximities, starting from a typical gravity model which includes only geography. Once other proximities are controlled for, the role conferred on geographic distance slightly alters, confirming our concerns that a bias is introduced, if these factors are neglected. Geographical and other distances may partially overlap, but each feature has a different, independent effect on mobility. As one can note, all coefficients mildly vary across specifications.

Each geographic coefficient of column (1) in Table 1 captures the difference between knowledge flows diffused in geographic space to knowledge flows within an area of $300 \mathrm{~km}$, which is our benchmark area. For example, the coefficient of Neighboring Countries [ $>300 \mathrm{Km}$ ] implies that neighboring countries that their geographic centers are located in more than $300 \mathrm{~km}$ apart, exchange about 45\% $\left(=1-e^{-0.595}\right)$ less inventors to what they would exchange within a distance of $300 \mathrm{~km}$. In other words, on crossing a distance of $300 \mathrm{~km}$, knowledge, based on inventor flows, diminishes to about $55 \%$. Further, the coefficient of Distance [ $<1110 \mathrm{Km}$ shows that non-neighboring countries that their geographic centers are located within $1110 \mathrm{~km}$ exchange about $61 \%\left(=1-e^{-0.946}\right)$ less knowledge than what neighboring countries with their geographic centers located less than 300 miles apart would exchange. The coefficients of Distance $[1110-1500 \mathrm{Km}]$ and Distance $[>1500 \mathrm{Km}]$ show that as distance grows the flows of inventors are further dissipated; the exchange of inventors between countries that their geographic centers are located between 11,100 and $1500 \mathrm{~km}$ (more than $1500 \mathrm{~km}$ apart) drops to $34 \%$ (20\%) compared to what they would exchange if their geographical enters were located within a distance of $300 \mathrm{~km}$.

In sum, geographic proximity plays an important role in shaping the spatial location choices of migrant inventors. The general finding in the literature of the geographic localization of knowledge flows, exemplified via inventors' moves (Drivas et al., 2016; Miguélez and
Moreno, 2014) ${ }^{33}$ or via other mechanisms, namely patent citations (Jaffe et al., 1993) and merchandises trade (McCallum, 1995), also finds support in our study. ${ }^{34}$ Distance could be seen as informational barrier and serves as proxy for all types of informational frictions. Agents within a close geographical distance tend to know much more about each other and each other's business, technologies, and cultures because of higher direct interactions between their citizens.

Irrespective of the geographic distance, the presence of inventors in the origin and, most important, in the destination country positively associates with inventor moves. Holding all other variables constant, a one percent increase in the number of inventors in the host country (lnInventors $)_{i}$ ) would lead to about $0.85 \%$ increase in the inventor inflows. ${ }^{35}$ This is because the size of the inventors' community reflects job

\footnotetext{
${ }^{33}$ The studies of Miguélez and Moreno (2014) and Drivas et al. (2016) examine the effect of geographic proximity on inventor flows in Europe and the US, respectively. Both studies document a strong geographic effect on the stretch of inventors' flows. For example, the study of Miguélez and Moreno (2014) find the geographic impact to range from -1.45 to -1.54 , which is somewhat larger than ours (-0.595 to -1.602) and Drivas et al. (2016) show only $1.7 \%$ of knowledge embodied in inventors crosses the vicinity of 500 miles and this percentage remains unaltered for any farther traveled distance implying that the die-out effect is large and sharp.

${ }^{34}$ Patent-citation literature, initiated by the seminal work of Jaffe et al. (1993) and followed by numerous subsequent studies (Branstetter, 2001; Mancusi, 2008; Peri, 2005), traces-out technological learning via citations of patents. The principal assumption is that a citation from a patent to another indicates that inventors of the latter patent knew and used the former. A separate volume of literature has documented the negative impact of geographic distance and borders on the flows of merchandize trade (Chen, 2004; McCallum, 1995; Wolf, 2000).

${ }^{35}$ The logit coefficient can be read as follows: A one percent increase in the number of inventors in the host country leads to a $0.19 \%$ decrease in the probability of belonging to the "strictly zero" group - that is, the probability of zero bilateral mobility.
} 
Table 1

ZINB Estimates of international inventor mobility (dep. var.: Flows $s_{i j t}$ ).

\begin{tabular}{|c|c|c|c|c|c|c|}
\hline & \multicolumn{2}{|l|}{ FromAllCountries } & \multicolumn{2}{|c|}{ From top 5 most innovative ${ }^{a}$} & \multicolumn{2}{|c|}{ From $^{25}$ less innovative ${ }^{b}$} \\
\hline & \multicolumn{2}{|l|}{ to All Countries } & \multirow{3}{*}{$\begin{array}{l}\text { to Low } 25 \\
\text { (NB estimates) } \\
\text { (2) }\end{array}$} & \multirow{3}{*}{$\begin{array}{l}\text { to All } \\
\text { (NB estimates) } \\
\text { (3) }\end{array}$} & \multirow{3}{*}{$\begin{array}{l}\text { to Top } 5 \\
\text { (NB estimates) } \\
\text { (4) }\end{array}$} & \multirow{3}{*}{$\begin{array}{l}\text { to All } \\
\text { (NB estimates) } \\
\text { (5) }\end{array}$} \\
\hline & (NB estimates) & (Logit estimates) & & & & \\
\hline & & & & & & \\
\hline \multirow[t]{2}{*}{ Neighbouring Countries $[>300 \mathrm{Km}]$} & $-0.595^{* * *}$ & $11.08^{* * *}$ & -0.382 & -0.114 & -0.141 & $-0.664^{* * *}$ \\
\hline & $(0.205)$ & $(1.771)$ & $(0.304)$ & $(0.378)$ & $(0.434)$ & $(0.208)$ \\
\hline \multirow[t]{2}{*}{ Distance $[<1110 \mathrm{Km}]$} & $-0.946^{* * *}$ & $11.08^{* * *}$ & $-0.765^{* * *}$ & $-0.758 * *$ & -0.148 & $-0.991^{* * *}$ \\
\hline & $(0.198)$ & $(1.315)$ & $(0.275)$ & $(0.371)$ & $(0.445)$ & $(0.215)$ \\
\hline \multirow[t]{2}{*}{ Distance $[1110-1500 \mathrm{Km}]$} & $-1.073^{* * *}$ & $11.26^{* * *}$ & -0.945 & -0.828 & -0.129 & $-1.145^{* * *}$ \\
\hline & $(0.206)$ & $(1.298)$ & $(0.269)$ & $(0.343)$ & $(0.463)$ & $(0.218)$ \\
\hline \multirow[t]{2}{*}{ Distance $[>1500 \mathrm{Km}]$} & $-1.602^{* * *}$ & $10.15^{* * *}$ & $-1.510^{* * *}$ & $-1.503^{* * *}$ & -0.389 & $-1.207^{* * *}$ \\
\hline & $(0.220)$ & $(1.488)$ & $(0.367)$ & $(0.425)$ & $(0.494)$ & $(0.242)$ \\
\hline \multirow[t]{2}{*}{ Density $_{i}$} & -0.037 & $0.039^{* * *}$ & -0.055 & -0.032 & $0.652^{*}$ & 0.030 \\
\hline & $(0.050)$ & $(0.013)$ & $(0.108)$ & $(0.087)$ & $(0.373)$ & $(0.060)$ \\
\hline \multirow[t]{2}{*}{ Density $_{j}$} & $-0.084^{*}$ & $-0.092^{* * *}$ & $0.389 * * *$ & $-0.421^{* * *}$ & -0.067 & $-0.158^{* * *}$ \\
\hline & $(0.044)$ & $(0.018)$ & $(0.102)$ & $(0.152)$ & $(0.086)$ & $(0.057)$ \\
\hline \multirow[t]{2}{*}{ lnInventors $_{i}$} & $0.853^{* * *}$ & -0.194 & $0.801^{* * *}$ & $0.858^{* * *}$ & 0.248 & $0.820^{* * *}$ \\
\hline & $(0.071)$ & $(0.130)$ & $(0.166)$ & $(0.130)$ & $(0.330)$ & $(0.090)$ \\
\hline \multirow[t]{2}{*}{ lnInventors $_{j}$} & $0.250^{* * * *}$ & $-0.414^{* * *}$ & $-0.445^{*}$ & -0.283 & -0.917 & $-0.158^{* *}$ \\
\hline & $(0.058)$ & $(0.144)$ & $(0.228)$ & $(0.188)$ & $(0.852)$ & $(0.068)$ \\
\hline \multirow[t]{2}{*}{ TechEffortDistance } & $0.365^{* * *}$ & -0.055 & 0.366 & 0.340 & 0.193 & 0.178 \\
\hline & $(0.112)$ & $(0.316)$ & $(0.292)$ & $(0.263)$ & $(0.208)$ & $(0.130)$ \\
\hline \multirow[t]{2}{*}{ TechSpecialisationSimilarity } & $0.531^{* * *}$ & $-2.774 * *$ & $1.644^{* *}$ & $1.249 * * *$ & $1.352^{* *}$ & $0.533^{*}$ \\
\hline & $(0.191)$ & $(1.167)$ & $(0.743)$ & $(0.656)$ & $(0.575)$ & $(0.304)$ \\
\hline \multirow[t]{2}{*}{ LinguisticSimilarity } & $0.265^{* * *}$ & -0.170 & $0.317 * * *$ & $0.328^{* * *}$ & $0.451 * * *$ & $0.486^{* * *}$ \\
\hline & $(0.089)$ & $(0.736)$ & $(0.060)$ & $(0.068)$ & $(0.174)$ & $(0.183)$ \\
\hline \multirow[t]{2}{*}{ ReligionSimilarity } & $0.298^{* * *}$ & -0.892 & 0.604 & 0.544 & 0.619 & $0.504^{* * *}$ \\
\hline & $(0.096)$ & $(0.987)$ & $(0.724)$ & $(0.964)$ & $(0.693)$ & $(0.111)$ \\
\hline \multirow[t]{2}{*}{ Trade $_{i j}$} & $0.330 * *$ & $-19.3^{* *}$ & 0.457 & 0.432 & 3.514 & $0.571^{* * *}$ \\
\hline & $(0.155)$ & $(8.415)$ & $(0.342)$ & $(0.423)$ & $(2.298)$ & $(0.190)$ \\
\hline \multirow[t]{2}{*}{ Institutions $_{i}$} & $0.199 *$ & $-2.262^{* * *}$ & $1.059 * * *$ & $0.791 * *$ & 0.933 & 0.911 \\
\hline & $(0.111)$ & $(0.489)$ & $(0.390)$ & $(0.376)$ & $(0.806)$ & $(0.814)$ \\
\hline \multirow[t]{2}{*}{ Institutions $_{j}$} & 0.016 & 0.416 & -0.345 & -0.125 & -0.123 & -0.189 \\
\hline & $(0.110)$ & $(0.669)$ & $(0.580)$ & $(0.510)$ & $(0.206)$ & $(0.158)$ \\
\hline HumanCapital $_{i}$ & 0.023 & $0.855^{* *}$ & 0.232 & 0.222 & $0.495^{* * *}$ & 0.174 \\
\hline & $(0.114)$ & $(0.392)$ & $(0.201)$ & $(0.188)$ & $(0.143)$ & $(0.136)$ \\
\hline HumanCapital $_{j}$ & 0.099 & -0.056 & 0.331 & 0.686 & 0.160 & 0.101 \\
\hline & $(0.115)$ & $(0.458)$ & $(0.333)$ & $(0.688)$ & $(0.183)$ & $(0.128)$ \\
\hline Observations & 11,310 & 11,310 & 1625 & 1885 & 1625 & 9425 \\
\hline Nonzero observations & 5056 & 5056 & 797 & 1056 & 1058 & 4000 \\
\hline LR test for overdispresion & 28,000 & & 1708 & 5558 & 3907 & 13,000 \\
\hline p-value & 0.000 & & 0.000 & 0.000 & 0.000 & 0.000 \\
\hline Vuong statistic & 8.80 & & 4.48 & 3.34 & 5.24 & 6.18 \\
\hline $\mathrm{p}$-value & 0.000 & & 0.000 & 0.004 & 0.000 & 0.000 \\
\hline McFadden's $R^{2}$ & 0.313 & & 0.358 & 0.331 & 0.307 & 0.322 \\
\hline
\end{tabular}

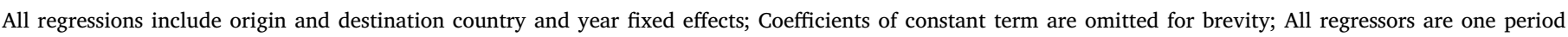

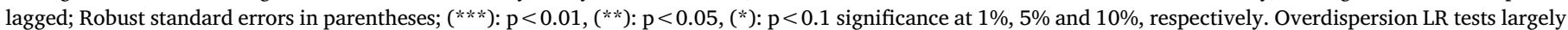

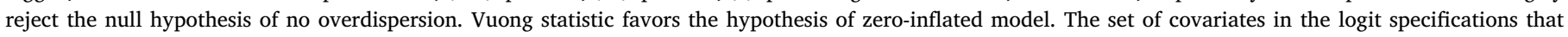

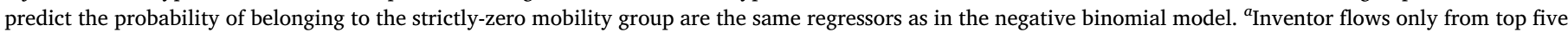

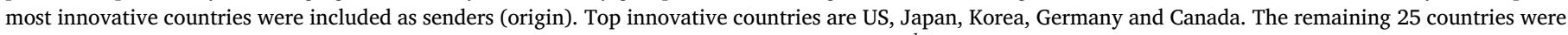

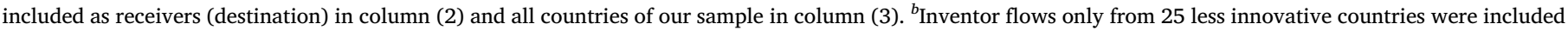

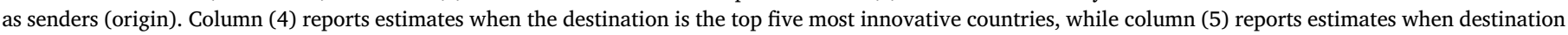
is all countries of our the sample.

opportunities and synergies among inventors and therefore is an attractive feature of the recipient country (Maggioni and Uberti, 2009; Miguélez, 2016; Miguélez and Moreno, 2013a). Countries that have a large pool of inventors, attract more inventors as well as send more inventors out (about $0.25 \%$ for a one percent increase in the number of inventors at home), as the estimate of the number of inventors in the origin country (lnInventors $_{j}$ ) indicates. Furthermore, the density (Density) of the population in the destination or origin country appears to be negatively related with the flows of inventors. However, only the origin's country density is statistically significant; the more dense is the home country, less inventors move out. Arguably, dense, urban areas may have a larger supply of scientists, producer and consumer amenities, and therefore such association could be observed.

Besides the geographical proximity, countries located close to each other may exchange more knowledge with each other simply because of the technological effort they pour and/or technological similarity specialization in their production. As the literature has argued, investment in R\&D and human capital makes a region attractive to talented individuals (Lucas, 1988). This is indeed what our results support; a one unit increase in technological effort distance, TechEffortDistance, between countries, increases inventor inflows at the host country by about $44 \%$. A country may also receive more inventor flows from another country with technological sector specialization as itself than from a country with completely dissimilar technological specialization production structure. Specifically, a unit increase in structural similarity, TechSpecialisationSimilarity (i.e., countries become perfectly identical with respect to their patent portfolio), increases the exchange of inventors by about $70 \%$ compared to countries with completely mismatched patent portfolio. Apparently, technological specialization is important for inventor's mobility as inventors are expected to benefit 
more from other inventors who work in the same or related technologies (Bode, 2004; Peri, 2005).

Cultural closeness between origin and destination country also shapes the flows of inventors. As the coefficient of the LinguisticSimilarity shows countries that share common language are about 30\% more probable to attract inventor flows than countries that do not. Somewhat greater is the effect of religion similarity (ReligionSimilarity). Countries with identical religion composition exchange about $35 \%$ more inventors than countries with virtually no common religion background. These findings are in line with other related studies (Miguélez and Moreno, 2014; Ortega and Peri, 2013) that corroborate the significance of common cultural roots for the individuals' mobility. The empirical trade literature also documents evidence on the role of religious bonds between trading partners in shaping bilateral trade flows (De Groot et al., 2004). Besides of making people feel more 'at home', cultural affinities facilitate the development of trust and networks of economic agents, smooth out communication problems and help the managing and administration of a common project.

Bilateral trade linkages between countries is also an important contributor. A one percent increase in the bilateral trade intensity increases inventors' mobility between the trading partners by almost $39 \%$. Trade may itself be a cause of innovative activities, as predicted by global-economy models of endogenous innovation and growth (Grossman and Helpman, 1991; Young, 1991). More innovation could also relate to more flows of inventors as certain links and information contacts are developed between trading partners.

Institutional variables, quality of government regulations and knowledge (human capital), carry the right sign; the better they are, the more attractive a place becomes. However, only the quality of regulations at the host country has a statistically significant effect as one unit increase of their quality associates with a $22 \%$ increase in the inventor inflows.

Table A6 in the Appendix explores further the sensitivity of our results by using alternative proxies for the institutional environment and human capital. However, in all sensitivity analyses we perform, the number of observations drop almost by half, due to data limitations. Regarding human capital and the public spending on tertiary education measure used here, we employ, in column (1), the share of population in science technology engineering and mathematics (STEM) (Ortega and Peri, 2013) and, in column (2), the human resources devoted in science and technology (HRST) (Miguélez and Moreno, 2014). Estimates carried the expected sign but only the HRST at destination was found to be statistically significant with a $3.5 \%$ association with inventor inflows. ${ }^{36}$

Additionally, we explore labour market institutions on shaping inventors' mobility and particularly the employment protection legislation $(E P L)$. According to column (3), we find that the stricter the EPL at the host country, the larger the inflow of inventors is, as a one unit increase in the stringency of the EPL, associates with a $12.7 \%$ increase in the inventors' inflows. Different patterns of innovation specialization could require different types of labour market regulations. For instance, in incremental innovation patterns (as it is mainly the case in Germany), stable and cooperative relationships between employers and employees are functional to the incremental path, while in countries which specialize in emerging radically new technologies (for instance, UK and US) more relaxed EPL is conductive to this path (Soskice, 1997). ${ }^{37}$ Furthermore, we examine whether Eurozone or

\footnotetext{
${ }^{36}$ In place of quality of regulations, we also used an index that captures the easiness of doing business; estimates, available upon request, were statistically insignificant and size-wise similar to the substituted variable.

${ }^{37}$ Empirical evidence by Griffith and Macartney (2014) shows that the optimal level of investment in radical innovation decreases with EPL, but that the optimal level of investment in incremental innovation increases with EPL.
}

Schengen membership associates with more flows. Estimates are shown in column (4). We find that Schengen countries exchange about 19\% more inventor flows compared to non-member countries. Eurozone membership has also a positive but statistically insignificant impact. ${ }^{38}$

Finally, we re-estimate our zero-inflated negative binomial model using different sub-sets of covariates in the logit part of the model. Results, available upon request, did not change in any significant manner. Overall, our results remain stable across different specifications, alternative definitions and different taxonomies of distance.

We, therefore, conclude that geographic proximity, technological closeness and cultural similarity across countries appear to greatly shape the flows of inventors with the technological similarity in the production structure to exert the largest influence. Furthermore, the size of inventors community at the host country, intense bilateral trade linkages and quality institutions, regulations in particular, are conductive factors to attracting highly skilled migrants.

Next, we explore whether the importance of the aforementioned proximities and institutional factors vary depending on the country of origin of the inventors: inventors, who move from the most innovative countries elsewhere, and those who move from the rest -the less innovative- countries of our sample. Technological advanced countries in our sample are: US, Japan, Korea, Germany and Canada, which rank very high in R\&D spending and number of patents and together account for more than $90 \%$ of the WIPO patents. We would like to note here that as our inference is based on different samples, we refrain from comparing estimates across groups; rather, we intent to highlight the factors that are important mobility drivers for each specific type of flows.

Geography does not appear to be an important restriction for inventors originated from the most innovative countries, as column (1) shows. This finding emerges particularly strong for inventor flows originating from countries with less prosperous innovation backgrounds and aim to move to frontier countries; in this class of inventors, gravity plays no role at all, as estimates in column (4) document - apparently, frontier countries are attractive places to inventors from less technologically advanced countries irrespective of the geographic distance. Geography, however, seems to exert a heavy toll on inventors' moves from less innovative countries to all countries in our sample, as estimates in column (5) show.

The main driver of both types of flows to relocate is technological proximity and particularly the technological similarity in the production structures of the home and host country. Cultural proximity is appreciated from inventors originating from less technologically advanced economies and, to a certain extent, from their peers from highinnovative economies. Potential collaboration with local fellows at the destination is important for inventors from both advanced and less advanced innovative economies; the quality of institutions at the destination is crucial for the former group, while human capital at the host country is significant factor for the latter group of inventors.

We can visualize some of our results with the use of a graph. Fig. 3 below depicts the estimated (dashed line) along with the actual (bold line) values of the geographic distance on inventor flows. The first panel shows the actual and estimated decay of inventor flows moving out of a nearby area of $300 \mathrm{Km}, 1110 \mathrm{Km}$, and $1500 \mathrm{Km}$. In similar fashion, the second and third panel present inventor flows originating only from the most and the least values countries, respectively.

The graphical evidence confirms the significant drop in the mobility of inventors for distances larger than $700 \mathrm{~km}$. Within a distance of $700 \mathrm{~km}$, there are four pairs of countries (Czech Republic and Germany,

\footnotetext{
${ }^{38}$ We further considered additional controls, namely taxes and wages. Our estimates shown that higher top marginal tax rate at the host (home) country relates negatively (positively) to inventor inflows (outflows), as expected, but results were statistically insignificant. Perhaps, such differences would be of importance for just a share of inventors, the very top ones (Akcigit et al., 2016). Similar evidence was supported for the wages.
} 

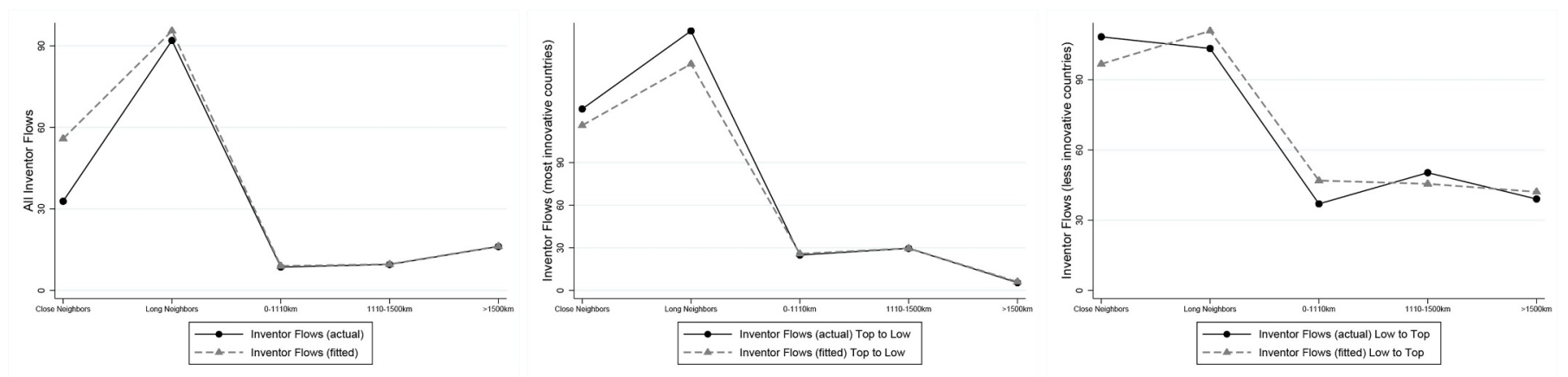

Fig. 3. Decay of inventor flows due to geographical distance.

Table 2

ZINB Estimates of international inventor and non-inventor mobility (dep. var.: Flows $s_{n i}$ ijt).

\begin{tabular}{|c|c|c|c|c|}
\hline & \multicolumn{2}{|l|}{ Inventors* } & \multicolumn{2}{|c|}{ Non - inventors* } \\
\hline & NB & logit & NB & logit \\
\hline \multirow[t]{2}{*}{ Neighbouring Countries [ $>300 \mathrm{Km}]$} & $-0.612^{* * *}$ & 1.521 & $-1.176^{* * *}$ & $1.815^{*}$ \\
\hline & $(0.251)$ & $(1.323)$ & $(0.287)$ & $(1.067)$ \\
\hline Distance $[<1110 \mathrm{Km}]$ & $\begin{array}{l}-0.981^{* * *} \\
(0.220)\end{array}$ & $\begin{array}{l}0.178 \\
(1.755)\end{array}$ & $\begin{array}{l}-1.525^{* * *} \\
(0.246)\end{array}$ & $2.203^{* * *}$ \\
\hline \multirow{2}{*}{ Distance $[>1500 \mathrm{Km}]$} & $-1.870^{* * *}$ & 1.229 & $-2.534^{* * *}$ & $2.574^{* * * *}$ \\
\hline & $(0.253)$ & $(1.838)$ & $(0.269)$ & $(0.847)$ \\
\hline \multirow[t]{2}{*}{ Density $_{i}$} & -0.059 & $-0.036 * *$ & 0.052 & $-0.027^{* * *}$ \\
\hline & $(0.058)$ & $(0.015)$ & $(0.041)$ & $(0.009)$ \\
\hline \multirow[t]{2}{*}{ Density $_{j}$} & -0.046 & $-0.042^{* *}$ & $-0.086^{* *}$ & -0.010 \\
\hline & $(0.049)$ & $(0.017)$ & $(0.037)$ & $(0.011)$ \\
\hline InInventors $_{i}$ & $0.689^{* * * *}$ & $-0.772^{* *}$ & $0.123^{* *}$ & -0.012 \\
\hline \multirow[t]{2}{*}{ TechSpecialisationSimilarity } & $0.470^{* k *}$ & -0.896 & 0.118 & $-2.237^{* * *}$ \\
\hline & $(0.155)$ & $(1.370)$ & $(0.350)$ & $(0.700)$ \\
\hline \multirow[t]{2}{*}{ LinguisticSimilarity } & $0.302^{* * *}$ & 0.011 & $0.569^{* * *}$ & $-15.81^{* * *}$ \\
\hline & $(0.115)$ & $(0.822)$ & $(0.154)$ & $(0.580)$ \\
\hline \multirow[t]{2}{*}{ ReligionSimilarity } & $0.366^{* * *}$ & -0.370 & $0.584 * * *$ & $-2.535^{* * *}$ \\
\hline & $(0.183)$ & $(2.086)$ & $(0.140)$ & $(0.741)$ \\
\hline \multirow[t]{2}{*}{ Trade $_{i j}$} & $0.231^{* *}$ & -60.53 & 0.377 & $-9.163^{* * *}$ \\
\hline & $(0.113)$ & $(39.16)$ & $(0.893)$ & $(3.171)$ \\
\hline \multirow[t]{2}{*}{ Institutions $_{i}$} & $0.146^{* *}$ & $-3.112^{* * *}$ & $0.312^{* * *}$ & 0.330 \\
\hline & $(0.063)$ & $(0.589)$ & $(0.008)$ & $(0.379)$ \\
\hline \multirow[t]{2}{*}{ Institutions $_{j}$} & -0.173 & $-1.549^{* * *}$ & $-0.338^{* * *}$ & $0.815^{* *}$ \\
\hline & $(0.189)$ & $(0.695)$ & $(0.009)$ & $(0.393)$ \\
\hline \multirow[t]{2}{*}{ HumanCapital $_{i}$} & 0.212 & $1.345^{* *}$ & $0.355^{* * * *}$ & $1.577^{* * *}$ \\
\hline & $(0.135)$ & $(0.624)$ & $(0.099)$ & $(0.268)$ \\
\hline
\end{tabular}

All regressions include origin and destination country and year fixed effects; Coefficients of constant term are omitted for brevity; All regressors are one period lagged; Robust standard errors in parentheses; $(* * *): p<0.01,(* *): p<0.05,(*): p<0.1$ significance at $1 \%, 5 \%$ and $10 \%$, respectively. Overdispersion LR tests largely reject the null hypothesis of no overdispersion. Vuong statistic favors the hypothesis of zero-inflated model. The set of covariates in the logit specifications that predict the probability of belonging to the strictly-zero mobility group are the same regressors as in the negative binomial model. *Our sample includes 22 countries. Due to lack of data eight countries (Bulgaria, Cyprus, France, Estonia, Greece, Hungary, Ireland and Portugal) are dropped from our initial sample.

USA and Canada, Germany and Austria, and Germany and France) that exchange large flows of inventors and drive upwards the graph. Overall, knowledge flows, exemplified by the mobility of inventors, are rather geographically confined in space. Furthermore, one can observe that actual and estimated values are very close to each other indicating a good fit of our model. 


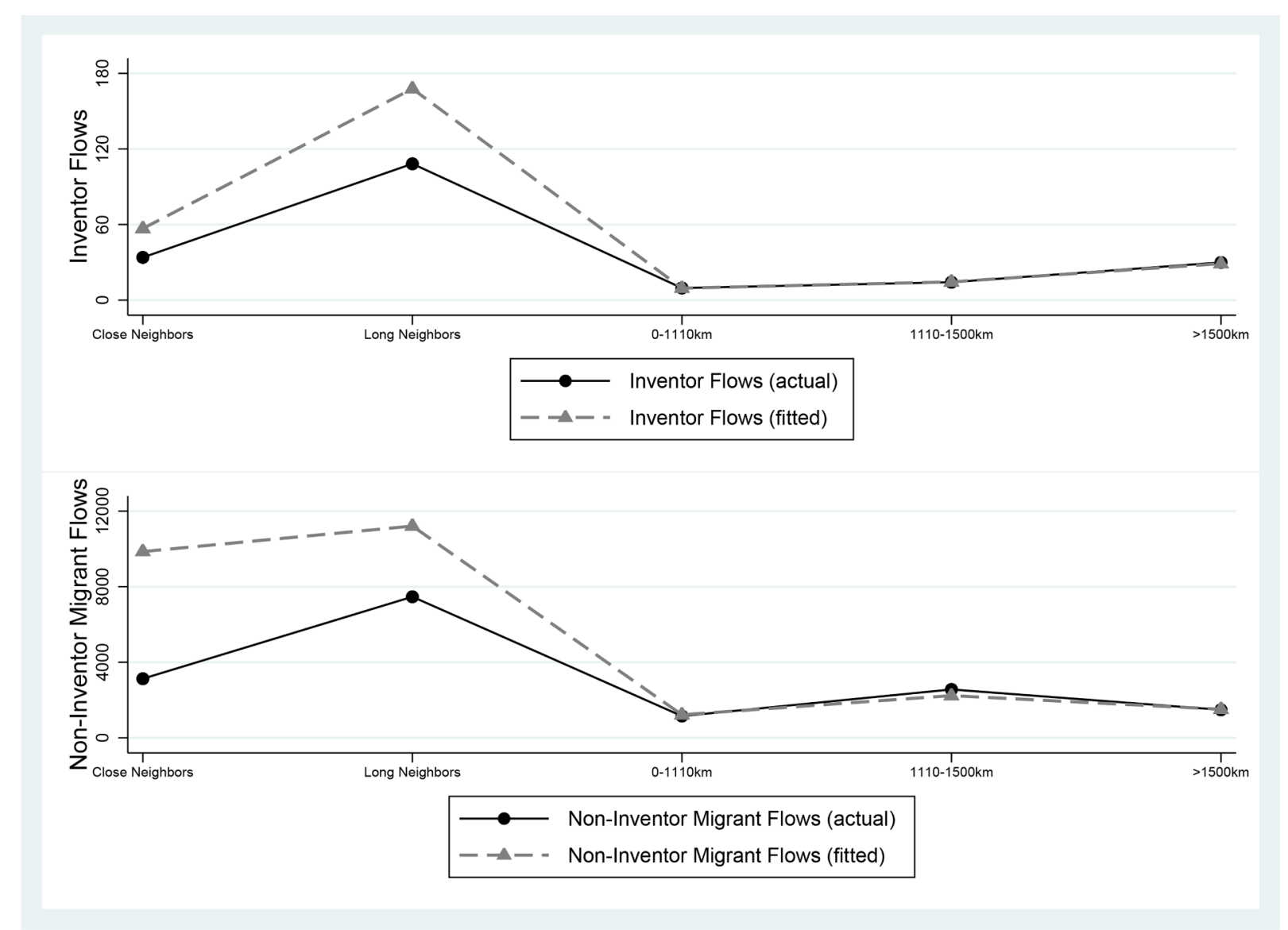

Fig. 4. Decay of inventor \& migrant flows due to geographical distance.

Table 3

Elasticities of innovation production function (dep. var.: $\log$ of patents).

\begin{tabular}{|c|c|c|c|}
\hline & $\begin{array}{l}\text { All countries }^{a} \\
\text { (i) }\end{array}$ & $\begin{array}{l}\text { Top } 5 \text { Most Innovative } \\
\text { (ii) }\end{array}$ & $\begin{array}{l}\text { All countries (weighted) } \\
\text { (iii) }\end{array}$ \\
\hline $\ln R \& D_{\text {own }}$ & $\begin{array}{l}0.822^{* * * *} \\
(0.168)\end{array}$ & $\begin{array}{l}0.769^{* * * *} \\
(0.145)\end{array}$ & $\begin{array}{l}0.798^{* * * *} \\
(0.130)\end{array}$ \\
\hline $\ln R \& D_{\text {external }}$ & $\begin{array}{l}0.224 * * * \\
(0.076)\end{array}$ & & \\
\hline $\ln R \& D_{\text {externalTop }}$ & & $\begin{array}{l}0.242^{* *} \\
(0.115)\end{array}$ & \\
\hline $\ln R \& D_{\text {externalRelative }}$ & & & $\begin{array}{l}0.229^{* * * *} \\
(0.059)\end{array}$ \\
\hline Constant & $\begin{array}{l}10.88^{* * *} \\
(2.513)\end{array}$ & $\begin{array}{l}7.108^{* * *} \\
(1.902)\end{array}$ & $\begin{array}{l}6.676^{* * *} \\
(1.017)\end{array}$ \\
\hline$R^{2}$ & 0.884 & 0.782 & 0.820 \\
\hline Observations & 378 & 313 & 378 \\
\hline
\end{tabular}

All regressions include country and year fixed effects; All regressors are one period lagged; Robust standard errors reported in parentheses; $\ln R \& D_{\text {own }}$ is country's own R\&D stock; $\ln R \& D_{\text {external }}, \ln R \& D_{\text {externalRelative }}$, and $\ln R \& D_{\text {top }}$ are external available to a country inventor-weighted external R\&D stocks that originate from all, top five most innovative countries and better in innovation efficient countries, respectively; All R\&D stocks are constructed using country level R\&D spending and the perpetual inventory method (15\% depreciation rate) as in the conventional literature (Guellec and van Pottelsberghe de la Potterie, 2004; Hall et al., 2005); Fitted values of Eq. (1) are used to weight all external R\&D stocks; Coefficients of the variables in vector I namely, share of population with science, technology, engineering, and mathematics education and proprietor rights policies, were statistically insignificant and therefore omitted. $(* * *),(* *)$, and $(*)$ : significance at $1 \%, 5 \%$, and $10 \%$ level, respectively. ${ }^{a}$ All countries were included as senders (origin) of knowledge flows. All countries were included as receivers (destination) of knowledge flows. ${ }^{b}$ Only the top 5 innovative countries were included as senders (origin) of knowledge flows. Only the remaining 25 countries were included as receivers (destination) of knowledge flows. The top 5 most innovative countries in our sample are: the US, Japan, Korea, Germany and Canada. ${ }^{c}$ External flows are additionally weighted by $\rho=$ $\left(\frac{\text { Patents }}{R \& D}\right) /\left(\frac{\text { Patents }}{R \& D}\right)_{\text {leader }}$. 


\subsubsection{Comparison: What shapes the moves of non-inventor migrants?}

As an exercise, in one common framework described by Eq. (1), we also study the flows of non-inventor migrant individuals $\left(F l o w s_{n i} i j t\right)$. As not all 30 countries in our sample provide information on such migration flows, we narrow down our analysis to 22 countries. ${ }^{39}$ Estimates of non-inventor migrant flows are presented in column (2) of Table 2, below. For comparison purposes, column (1) reports estimates of Eq. (1) of inventor flows, but for the new sample of 22 countries.

Before embarking on the analysis, we would like to briefly discuss first some descriptives of non-inventor migrant flows. Over our sample period 2000-2012, an average pair of countries has exchanged about 2082 migrant individuals. As shown in Table A7 in the Appendix, the countries with the largest inflows are Germany $(3,540,019)$, the UK $(1,313,663)$ and Spain $(962,090)$ in Europe and the US $(1,183,853)$ and Japan $(938,482$ ). High mobility is observed between 38 (out of 459) country pairs (top $5 \%$ of the migrant flows distribution) - that is more than 9974 occurrences per year. Large migrant flows are reported from Poland to Germany $(1,577,493)$, Korea to Japan $(326,161)$, Italy to Germany $(300,308)$, US to Japan $(286,365)$ and Korea to the US $(280,900)$. Fig. A1 in the Appendix graphs country interactions (network) with the largest migrant moves. ${ }^{40}$

There are couple of points worth noting in this exercise. First, the geographic stretch of non-inventor migrant individuals is smaller than that of highly skilled migrants. For example, the flows of non-inventor migrants on crossing neighboring countries that their geographic centers are located more than $300 \mathrm{~km}$ apart diminish to about 30\% (= $\left.e^{-1.176}\right)$ to its in-300 area level, whereas the flows of inventors diminish to $54 \%$ for the same distance, as the coefficients of Neighboring Countries [ $>300 \mathrm{Km}$ ] indicate. Similarly, the flows of migrants (inventors) that cross a distance of $1500 \mathrm{~km}$ drop to $8 \%(15 \%)$ to what would flow within a distance of $300 \mathrm{~km}$. It appears that non-inventors are about 1.5 more geographically confined than inventors. The relative geographic stretch of skill is also confirmed by the study of Czaika and Parsons (2015), who examine migrations policies and geographic effects on the mobility of skillful and less skillful ordinary migrants.

Second, technological proximity, as expected, matters more for inventors than for non-inventor migrants; nevertheless it is also relevant for the latter. Our results show that a one unit increase in technological effort distance between countries, increases the inflows of migrants (inventors) by 19\% (47\%). Apparently, the technological level of the destination country and its distance to the origin is relevant for noninventor migrants as in this group there are individuals who are technically skilled (scientists, researchers, engineers, medical doctors among others) and therefore technological effort matters. The technological similarity in the production, however, is only relevant for the inventors and not for the other migrants. The inventor community at the host country is an attractive feature for non-inventor migrants; nevertheless, it has much smaller impact compared to that on inventors; perhaps, a large inventor community may offer more opportunities for synergies for a subset of migrants. Additionally, the presence of inventors, generally, reflects innovation capabilities of a country and economic growth potential.

Third, cultural proximity is about two times more important for non-inventor than for inventor migrants. Religion similarity, which captures a broad set of beliefs and attitudes important for shaping local culture and in turn innovative performance, is more important than linguistic similarity to both inventors and other migrants. We find that two countries with exactly same religion exchange $79 \%$ (44\%) more

\footnotetext{
${ }^{39}$ Due to lack of data, we dropped out eight countries: Bulgaria, Cyprus, France, Estonia, Greece, Hungary, Ireland and Portugal.

${ }^{40}$ Unfortunately, there is no information on the composition (engineers, doctors, scientists, etc) of the non-inventor flows to further analyze flows of sub-categories.
}

migrants (inventors) than countries that they do not. Also, two countries with exactly the same language exchange $77 \%$ (35\%) more migrants (inventors) than countries with dissimilar languages.

Quality of institutions play an important role for both types of flows. Bilateral trade is an important attractor for inventors, while human capital appears to be important to non-inventor migrants.

For robustness purposes, we use two alternative proxies for human capital, namely (i) the share of population in science technology, engineering and mathematics (STEM) and (ii) the human resources devoted in science and technology (HRST) at the host and origin, and reestimate specifications (1) and (2). Overall, despite the drop of observations by half, the estimated coefficients did not vary in any significant manner. Additionally, we find that STEM presence at the host country is positively related only with migrant flows (1.6\%), and when the HRST is used, estimates show that countries with high science and technology human resources attract more inventors $(4.6 \%)$ as well as migrants (4.4\%). We also add into specifications (1) and (2) the stringency of employment protection legislation (EPL) at the destination and home country. We find that strict employment protection at the destination country positively relates only with more inventor flows $(7.9 \%)$. Finally, we find no statistical significant impact of the 2007 financial crisis on either flows. ${ }^{41}$

We would like to note here that one should read these results with caution due to differences in definitions and measurement methods of migration patterns across countries. ${ }^{42}$

We can also graphically show the geographic stretch of inventor and non-inventor flows for this set of 22 countries. Fig. 4 below depicts the estimated (dashed line) along with the actual values (bold line) of geographic resistance factors on inventor and non-inventor migrant flows. As before, it shows the actual and estimated decay of inventor and non-inventor migrant flows moving out of a nearby area of $300 \mathrm{Km}$, $1110 \mathrm{Km}$, and $1500 \mathrm{Km}$.

The graph confirms the dramatic drop in the mobility of inventors and non-inventors alike for distances larger than $700 \mathrm{~km}$. Within the distance of $700 \mathrm{~km}$, however, there are strong inventor flows between Czech Republic and Germany, USA and Canada, Germany and Austria, and Germany and France, and large non-inventor flows between Poland and Germany, Austria and Germany, and Czech Republic and Germany that drive the patterns upwards. After the distance of $700 \mathrm{~km}$ there is a sharp drop in both flows. An important difference, however, is that for long distances, higher than $1500 \mathrm{~km}$, while the flows of non-inventors continue to significantly decay, there is a small increase in the inventor flows - most probably between European countries (UK and Germany) and the US or between asian countries and the US, as other factors, such as technology, may have stronger impact than gravity.

\subsubsection{Robustness}

A critical concern in any empirical analysis is endogeneity, which produces biased and inconsistent estimates. A way to alleviate such a concern is to run our estimations with all regressors in time lags, as we did so far.

However, omitted factors such as collaborations and networks among inventors not captured in our estimations may induce endogeneity issues. Furthermore, as relevant literature on trade (Eichengreen and Irwin, 1998) or migration (Anjonami and Hariri, 1992) flows has argued, historical linkages and hysteresis between pairs of countries may also influence the exchange of people or goods. Country-pair and year fixed effects, however, in all of our estimations account for all of unobserved and time invariant factors. In addition, we follow Wooldridge (2002) and allow for time lags in our dependent variable to control for any historical factors that are responsible for unobserved causes of migration. Table A8 in the Appendix

\footnotetext{
${ }^{41}$ Robustness analysis is available upon request.

${ }^{42}$ See De Beer et al. (2010) for a discussion.
} 
repeats estimation (1) from Table 1 but includes one-year (column b), two-year (column c) and three-year (column d) lags of the dependent variable as additional controls. Results show that all coefficients remain stable. While the three lagged variables have remained statistically significant, their coefficients are almost zero. Therefore, there is no strong indication that unobserved factors, related to historical linkages between countries, exert any significant influence on the current values of our inventor migration flows.

Next, we examine whether the presence of inventors at the destination country biases our results due to reverse causality. We aim for suitable instruments - not a trivial task, though - which must be uncorrelated to the unobservable time-varying error term and sufficiently correlated to the endogenous variable we want to instrument (i.e., the number of inventors at the host country). Following the literature, among the potential candidates are the stock of foreigners in a country's population (Akcigit et al., 2017a; 2017b; Hunt and Gauthier-Loiselle, 2010; Kerr and Lincoln, 2010) and innovation-enhancing institutions (Acemoglu et al., 2005; Caselli and Coleman, 2001) as it was discussed earlier in this paper. ${ }^{43}$ Column (e) presents the new estimates. Further columns ( $\mathrm{f}$ ) and $(\mathrm{g})$ instrument for technology proximity using as instruments the stock of foreigners, rule of law, and additionally, the presence of universities at the host country (Universities per capita). ${ }^{44}$

We apply two-stage residual inclusion (2SRI) estimation, the equivalent of two-stage least square (2SLS) for count data (Wooldridge, 2002). In doing so, we regress our endogenous variable(s) on the instruments in the first stage, conditional upon the other exogenous variables of the original model, and recover the predicted residuals of this estimation to plug them into our original model (without excluding our endogenous variable, the number of inventors at the host country); the inference is based on bootstrapping over all two-step procedure, 1000 iterations. The Hansen over-identification tests support no correlation between the instruments and the error term. In addition, the value of the $F$-statistic reassures us that the instruments cannot be judged as weak. The negative coefficient of the control term included tells us, furthermore, that the latent factor captured by the instruments is negatively correlated with cross-country inventors' mobility. Hence, endogeneity seems to cause a small downward bias in the number of inventors at the destination coefficient in our previous estimates. Note, however, that the bias is small and the control term is not statistically significant, therefore, the main conclusions of the analysis undertaken hold.

\subsection{Does inventor mobility contribute to local innovation activity?}

We have established thus far that inventor flows across countries are shaped by various proximities among other country level factors. These flows, however, do not necessarily support existence of externalities (and in particular of positive externalities) of knowledge on innovation. As Peri (2005) argues, available knowledge originating in other countries may very well bring a reduction in the unexplored innovation possibilities as it may push companies or the government to employ less able people in the R\&D sector. These effects may generate a zero or

\footnotetext{
${ }^{43}$ Data on foreign-born individuals (over country's population), who have residence in one country but were born in another country (Foreigners), are obtained from the WDI. Information on the rule of law (Rule of Law) comes from the World Bank, Worldwide Governance Indicators and captures perceptions of the extent to which agents have confidence in and abide by the rules of society and in particular the quality of contract enforcement, property rights, the police, and the courts.

${ }^{44}$ Universities contribute to innovation of a country via various channels, most notably through technology development, technology transfer (licensing of universities patenting to the market) and business spin-offs from university research (Goldstein and Renault, 2004; Veugelers and Rey, 2014). Data on number of universities per capita are derived from http://www.webometrics. info/en/node/54.
}

even negative net effect on the productivity of researchers in innovation. Recent evidence by Roper et al. (2017) on UK firms' innovation performance supports opposing (positive) knowledge diffusion and (negative) competition effects, which create the potential for either positive or negative local spillovers.

Therefore, the next task of this paper is to assess the effect of external available knowledge on country's innovation activity. In doing so, we estimate a function of innovation production and assess the effect of this particular channel of knowledge flows, i.e., inventors' mobility, on local production of innovation.

In its simple form, the output of a production of innovation of a region (country, in our case) is determined by the homegrown as well as by the external, but accessible (or 'borrowed') to the region technological knowledge of other regions (Drivas et al., 2016; Griliches, 1992; Peri, 2005) and can be expressed as follows:

$Q_{i t}=I_{i t}\left(A_{i t}\right)^{\delta}\left(A_{i t}^{\alpha}\right)^{\mu}$

where $Q$ is the innovative output produced in country $i$; $I$ is a set of innovation-enhancing institutions; $A$ is own, homegrown knowledge stock, proxied by R\&D stock accumulated from past and current R\&D investments in country $i$; and $A^{\alpha}$ is the stock of external and accessible (hence the $\alpha$ superscript) to country $i$ knowledge stock, proxied by R\&D accumulated in countries other than $i$ at time $t$.

Knowledge flows take place when an idea, generated in region, country or institution, is learned by another region, country or institution. If knowledge flows manage to perfectly and completely spill over, then the amount of external knowledge that eventually reaches country $i$ is simply the summation of all borrowed knowledge that comes from all other countries. In reality, however, the diffusion of knowledge flows across countries may be less than complete; only a share of research results from other countries reaches country $i$. Therefore, the external accessible to country $i$ R\&D activity can be described by:

$A_{i t}^{\alpha}=\sum_{j \neq i} \phi_{i j t} A_{j t}$

where $\phi_{i j}$ is the share of knowledge learned in country $i$.

Substituting Eq. (3) into Eq. (2) and by taking logs, Eq. (2) yields:

$\ln Q_{i t}=\gamma I_{i t}+\delta \ln A_{i t}+\mu \ln \left(\sum_{j \neq i} \phi_{i j t} A_{j t}\right)$

The dependent variable of Eq. (4) is the innovation output $\ln Q$, proxied by the log of number of patents (Patents) filed in a country at year $t$ and is a count variable. ${ }^{45}$

We apply ordinary least square (OLS) estimation, controlling for country and time fixed effects. ${ }^{46}$ The use of country and year fixed effects implies that time-varying institutional or policy differences across countries or any other factor changing with country and time, do not affect our estimates $\delta$ and $\mu$. We standardize $\phi$ as follows: $\phi_{i j t}=\left(F_{i j t} t\right.$ Inventors $\left.s_{j t}\right) /\left(F_{i t} /\right.$ Inventors $\left._{i t}\right)$, where $F_{i j t}$ is the inventor flows between country of origin $j$ and destination country, $i$, over the number of inventors at origin country, Inventors $s_{j t}$, while $F_{i t}$ is the total number of inventor flows from all countries at the destination over the number of inventors Inventors $s_{i t}$ at the destination country; $F_{i j t}$ are the fitted values of Eq. (1) (see Table 1, specification in column (4)). ${ }^{47}$

\footnotetext{
${ }^{45}$ Not all inventions are patented and further patents proxy a subset of innovative activity. It is though a reliable way to track innovation activity. The idea of using patents counts as a metric for innovation output to examine R\&D productivity dates at least back to Hausman et al. (1984) - for a more extensive review of early work of using patent counts consult Hall et al. (2001).

${ }^{46}$ The log is a monotonic transformation and, as there are no zero patents in our sample, we can use OLS to estimate Eq. 4.

${ }^{47}$ We also estimated Eq. (4) using the actual, raw flows of inventors in constructing $\phi$. The results, available upon request, changed only marginally, as the correlation between fitted and actual flows is 0.91 .
} 
Table 3 reports the estimated innovation elasticities. Column (i) reports estimated coefficients of country's own R\&D stock and external accessible to a country flow-weighted R\&D stock gained via the mobility of inventors channel. Column (ii) reports innovation elasticities, in similar fashion, but when external accessible flow-weighted R\&D stock originates only from the top five most innovative countries in our sample. In fact, this column includes the top five countries in the regressions only as senders of knowledge flows and the remaining 25 countries as receivers. Consequently, $A_{i j t}^{\alpha}$ in Eq. (4) is defined as $A_{i j t}^{\alpha}=\sum_{j \in T o p 5}\left(\phi_{i j t} A_{i j t}\right)$. This allows us to minimize potential endogeneity in estimating the coefficient $\mu$ of $A_{i j t}^{\alpha}$. Finally, as an exercise, column (iii) reports innovation elasticities when external accessible flow-weighted R\&D stock is weighted by the relative importance of country pairs in terms of their innovation efficiency, $\sum_{j \neq i} \phi_{i j t} \rho A_{j t}$, where $\rho=\frac{r_{j t}}{r_{i t}}$ and $r$ is a country's innovation efficiency $\left(\frac{\text { Patents }}{R \& D}\right)$ standardized by the innovation efficiency of the leader country $\left(\frac{\text { Patents }}{R \& D}\right)_{\text {leader }}$, i.e., the country with the highest innovation efficiency in each year in our sample, so $\rho=\left(\frac{\text { Patents }}{R \& D}\right) /\left(\frac{\text { Patents }}{R \& D}\right)_{\text {leader }}$.

As Table 3 shows, estimates of flows reported in columns (i) to (iii) are very close to each other. This alleviates concerns about endogeneity. Despite of the potential worsening of the endogeneity problem when external accessible R\&D stock originates from all countries, estimates are overall quite close across different specifications.

More specifically, results support that country's own $\left(\ln R \& D_{\text {own }}\right)$ as well as external accessible R\&D stock $\left(\ln R \& D_{\text {external }}\right)$ are important contributors to countries' innovation production. We find that a one percent increase of a country's own R\&D is associated with an increase in the local production of innovation from $0.77 \%$ (column ii) to $0.82 \%$ (column i).

Other countries' R\&D effort has also a positive effect on local production of patents. A one percent increase of external accessible inventor-weighted knowledge is associated with an increase in the production of innovation by about $0.224 \%$ (column i). The external inventor-weighted knowledge when only flows that originate from the top innovative countries are considered is $0.242 \%$. Apparently, the five most innovative countries in our sample invest heavily on home-produced technological knowledge, which in turn is transferred across other countries via the mobility of their inventors. Finally. when the external flows are weighted by the relative innovation efficiency competence of the countries, then a one percent increase of external flows, associates with a $0.229 \%$ increase in local patenting activity.

In a nutshell, external accessible knowledge that reaches a country via the channel of inventors' mobility matters. More particularly, countries benefit the most when external knowledge originates from the top-tier innovative countries, while there is a marginal higher benefit when knowledge comes from better in innovation efficiency countries than themselves compared to knowledge that originates from all countries.

Overall, our estimates of own R\&D elasticity (77-82\%) are in the vicinity of estimates reported in the international spillover literature, and in particular in the studies of Peri (2005) (60-80\%), Branstetter (2001) (72\%), Pakes and Griliches (1980) (61\%) and Bottazzi and Peri (2007) (78\%) among other studies. Furthermore, knowledge -carried through inventor moves- is relevant to local innovation production as it has a positive effect on a country's innovation activity. Our inventor-weighted R\&D estimates (22.4-24.2\%) are about half to those reported in Peri (2005) (40-50\%) and Peri (2005) (40-50\%) - these elasticities, however, refer to citationweighted and not to inventor-weighted external knowledge, as we discuss here - and larger than those reported in Drivas et al. (2016) for the case of the US. Our elasticity estimates corroborate with those reported in the studies of Hunt and Gauthier-Loiselle (2010), Crescenzi and Gagliardi (2015) and Miguélez and Moreno (2013a) which focus on inventor mobility and on average are about $15 \%$ to $20 \%$.

Summing up, we find that the flows of inventor movers carry technological knowledge, which is relevant to local innovation production as external accessible R\&D, gained through the inventors mobility channel, has a positive effect on a country's innovation activity.

\section{Conclusion}

Individuals are reservoirs of both skills and ideas and their location and mobility are keys to knowledge accumulation and diffusion. In advanced economies, innovation and technological knowledge have been both found to be strongly tied to the talented migrants. Thus far, only a scant few studies have studied the mobility of inventors and even fewer examined their impact on innovation performance.

This paper contributes to the literature by focusing on an understudied, yet important channel of knowledge diffusion and a great contributor to economic growth and convergence among countries: the mobility of patent inventors. Employing patent data to track their moves, we use a gravity model to perform an integral evaluation of the factors that shape the flows of these talented individuals. As a comparison, in the same framework, we also analyze flows of non-inventor migrants. Most importantly, we evaluate potential benefits of inventors' mobility on local innovation activity.

Our evidence shows that proximity matters for migration flows. Gravity emerges everywhere; in the mobility of inventor and non-inventor migrant workers. We find, however, that inventors are less geographically restricted and therefore their reach is beyond that of the non-inventor migrants. Similarity in technological structure of production between countries is the main driver of inventor moves. Quality regulatory environment and job opportunities at the destination as well as trade linkages between origin and host country are attractive factors for talented migrant individuals. Finally, knowledge and skills that move with the inventors have a significant positive impact on local innovation activity in the host country, whereas knowledge is not lost to the origin country. As with pollination, it seems all flowers benefit from the mobility of the bees and inventor mobility helps to diffuse knowledge that does not diminish in the process.

The implications of our findings for the literature are relevant. Theoretical trade-growth studies (Grossman and Helpman, 1991; Rivera-Batiz and Romer, 1991) have long emphasized the important consequences of knowledge flows for technology transfer and economic growth. Along with other important studies, this paper makes an effort towards this direction and empirically confirms the geographic scope of embodied knowledge flows as well as their economic impact.

The empirical analysis presented in the paper should be interpreted bearing in mind some key limitations. First we focused our attention on the mobility of inventors, a very specific class of skilled and innovative individuals. Second, our analysis shares the strengths as well as the limitations of other studies using patent data as a measure of innovation: they may under-represent actual innovation. Third, one must note here that inventors' mobility may not be equally important for all firms in a country. The attraction of highly skilled knowledgeable individuals can be more effective in enhancing local innovation when this is part of a country innovation strategy that stimulates the inclusion of these inflows into the network structure of the local economy. Future research should go into the direction of studying firm level dynamics and mobility of skilled individuals in the broader context of local, regional and national systems of innovation. ${ }^{48}$

Having acknowledged these limitations, we offer some policy considerations. Given the important economic contribution of inventors,

\footnotetext{
${ }^{48}$ This literature pioneered by Freeman (1987), Lundvall (1998), Howells (1999) and De la Mothe and Paquet (2012) takes a systemic approach to innovation, would emphasize the context of innovation processes and look at the in- and outflow of inventors as caused by and affecting the features and performance of innovation systems. The empirical literature here zooms in on collaboration, networks and the linkages in the innovation chain from knowledge and idea generation to product and service development and diffusion (Martinez-Roman et al., 2011; Strand and Leydesdorff, 2013; Zhao et al., 2015)
} 
countries should be more attentive to the quality, accountability and effectiveness of their home institutions and develop their immigration policies, as the latter could become more welcoming to skilled people. Fostering skilled migration is a powerful policy option. Active policies should be designed in order to remove existing barriers to labour mobility: from entry restrictions to institutional/regulatory barriers. Conversely, taking a hard line stance on immigration policy could inadvertently threaten a country's appeal to the brightest and best migrant innovators and thereby hamper its growth potential.

\section{CRediT authorship contribution statement}

Kyriakos Drivas: Investigation, Methodology. Claire Economidou: Conceptualization, Writing - review \& editing. Dimitrios Karamanis: Software, Data curation, Visualization. Mark Sanders: Supervision.

\section{Appendix A}

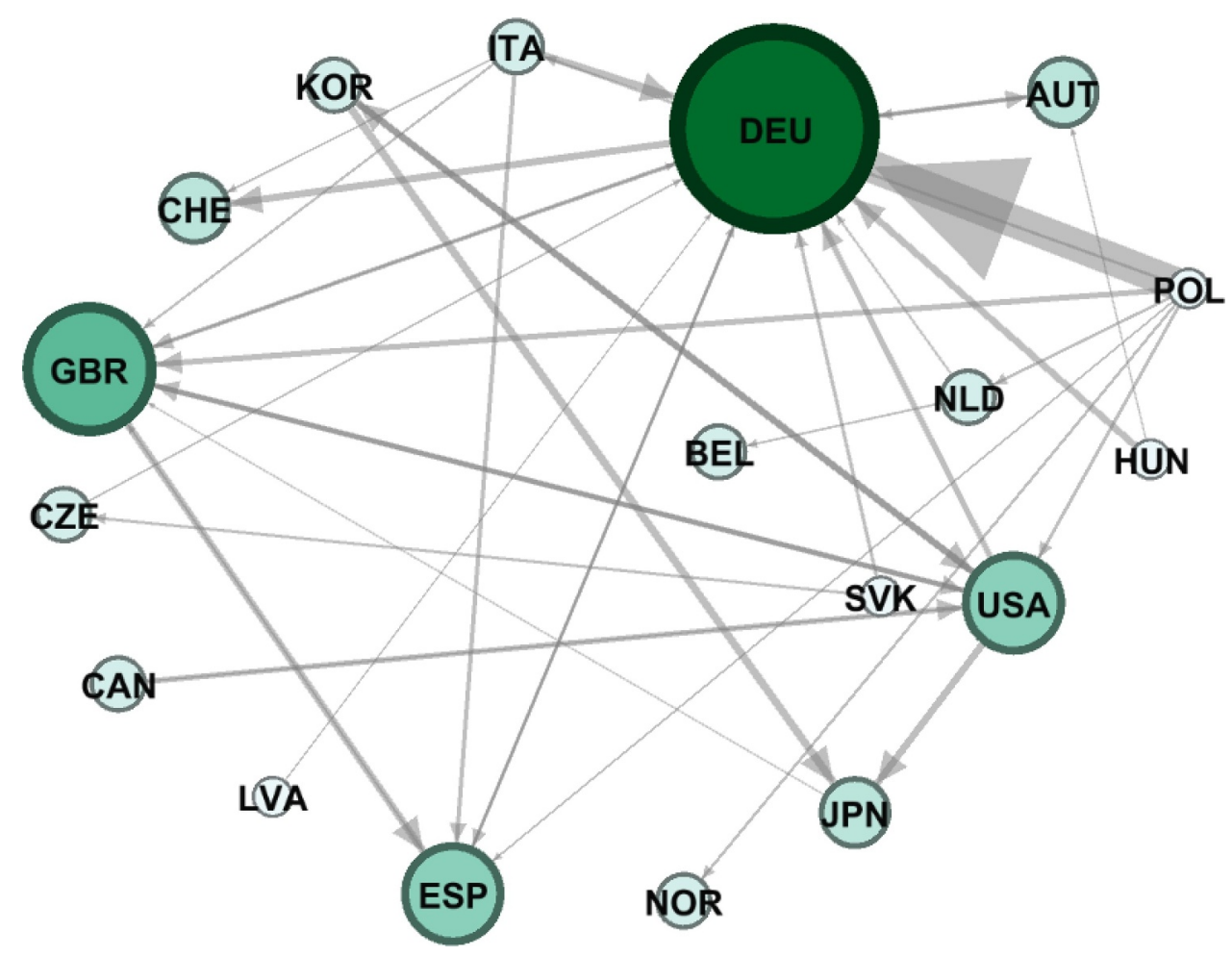

Fig. A1. Top 5\% non-inventor migrant flows across technologically advanced countries, 2000-2012. 
Table A1

List of Countries (and Membership to Eurozone, Schengen) .

\begin{tabular}{|c|c|c|c|}
\hline Countries & Abbreviation & Eurozone Member & Schengen Member \\
\hline Austria & AUT & YES (1999) & YES (1997) \\
\hline Belgium & BEL & YES (1999) & YES (1995) \\
\hline Bulgaria & BGR & & \\
\hline Canada & CAN & & \\
\hline Croatia & HRV & & \\
\hline Cyprus & CYP & YES (2008) & \\
\hline Czech Republic & CZE & & YES (2007) \\
\hline Denmark & DNK & & YES (2001) \\
\hline Estonia & EST & YES (2011) & YES (2007) \\
\hline Finland & FIN & YES (1999) & YES (2001) \\
\hline France & FRA & YES (1999) & YES (1995) \\
\hline Germany & DEU & YES (1999) & YES (1995) \\
\hline Greece & GRC & YES (1999) & YES (2000) \\
\hline Hungary & HUN & & YES (2007) \\
\hline Ireland & IRL & YES (1999) & \\
\hline Italy & ITA & YES (1999) & YES (1997) \\
\hline Japan & JPN & & \\
\hline Korea, Republic of & KOR & & \\
\hline Latvia & LVA & YES (2014) & YES (2007) \\
\hline Netherlands & NLD & YES (1999) & YES (1995) \\
\hline Norway & NOR & & YES (2001) \\
\hline Poland & POL & & YES (2007) \\
\hline Portugal & PRT & YES (1999) & YES (1995) \\
\hline Slovak Republic & SVK & YES (2009) & YES (2007) \\
\hline Slovenia & SVN & YES (2007) & YES (2007) \\
\hline Spain & ESP & YES (1999) & YES (1995) \\
\hline Sweden & SWE & & YES (2001) \\
\hline Switzerland & CHE & & YES (2008) \\
\hline United Kingdom & GBR & & \\
\hline United States & USA & & \\
\hline
\end{tabular}

Parentheses indicate the entry year.

Table A2

Summary statistics (30 OECD countries, 2000-2012).

\begin{tabular}{|c|c|c|c|c|c|c|}
\hline Proximity & Variable & Obs & Mean & St. Dev. & Min & Max \\
\hline Inventor Flows & Flows & 11,310 & 18.071 & 100.934 & 0 & 2415 \\
\hline \multirow{7}{*}{$\begin{array}{l}\text { Non-inventor Flows } \\
\text { Geographic }\end{array}$} & Flows $_{n i}$ & 5967 & $2,082.281$ & $7,074.274$ & 0 & 177,758 \\
\hline & Neighboring Countries $[<300 \mathrm{Km}]$ & 11,310 & 0.028 & 0.164 & 0 & 1 \\
\hline & Neighboring Countries $[>300 \mathrm{Km}]$ & 11,310 & 0.055 & 0.228 & 0 & 1 \\
\hline & Distance $[<1110 \mathrm{Km}]$ & 11,310 & 0.225 & 0.418 & 0 & 1 \\
\hline & Distance $[1110-1500 \mathrm{Km}]$ & 11,310 & 0.156 & 0.363 & 0 & 1 \\
\hline & Distance $[>1500 \mathrm{Km}]$ & 11,310 & 0.536 & 0.499 & 0 & 1 \\
\hline & Density & 11,310 & 13.614 & 11.840 & 0.308 & 49.930 \\
\hline Inventors & Inventors & 11,310 & $9,308.079$ & $21,627.280$ & 3 & 133,960 \\
\hline \multicolumn{7}{|l|}{ Technological } \\
\hline & TechEffortDistance & 11,310 & 0.968 & 0.779 & 0.00003 & 3.569 \\
\hline & TechSpecialisationSimilarity & 11,310 & 0.795 & 0.150 & 0.130 & 0.997 \\
\hline \multicolumn{7}{|l|}{ Cultural } \\
\hline & LinguisticSimilarity & 11,310 & 0.048 & 0.214 & 0 & 1 \\
\hline & ReligionSimilarity & 11,310 & 0.174 & 0.208 & 0 & 0.873 \\
\hline \multirow[t]{3}{*}{ Institutions } & Regulation Quality & 11,310 & 1.244 & 0.403 & -0.039 & 2.077 \\
\hline & Rule of Law & 11,310 & 1.198 & 0.583 & -0.223 & 1.999 \\
\hline & $E P L$ & 9367 & 2.47 & 0.587 & 1 & 4.1 \\
\hline \multicolumn{7}{|l|}{ HumanCapital } \\
\hline & TertiarySpending & 11,310 & 1.341 & 0.513 & 0.540 & 2.71 \\
\hline & STEM & 7279 & 25.810 & 5.315 & 2.112 & 35.2 \\
\hline & $H R S T$ & 6032 & 40.888 & 8.017 & 21.400 & 55.4 \\
\hline \multirow{3}{*}{$\begin{array}{l}\text { Bilateral Trade Intensity } \\
\text { Instruments }\end{array}$} & Trade & 11,310 & 0.0414 & 0.0860 & 0.00001 & 1.428 \\
\hline & Foreigners & 11,310 & 9.771 & 5.845 & 0.528 & 27.655 \\
\hline & Universities per capita & 11,310 & 10.249 & 5.024 & 3.947 & 27.528 \\
\hline Innovation Activity & Patents & 10,962 & $39,289.8$ & 104,536 & 8 & 542,815 \\
\hline
\end{tabular}




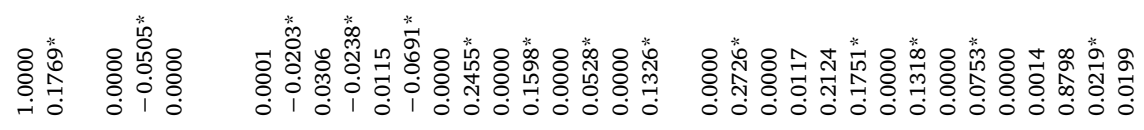




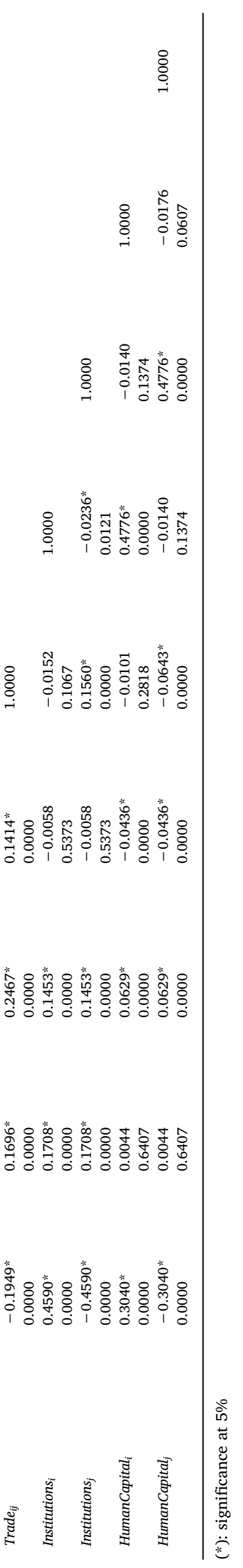

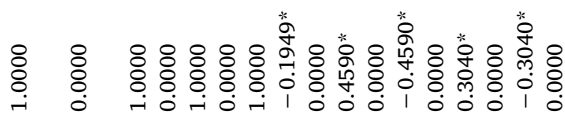

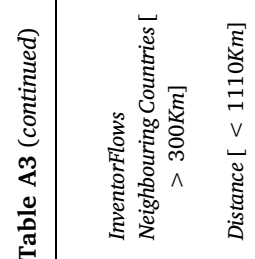

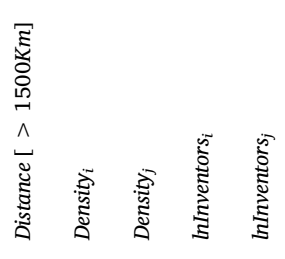

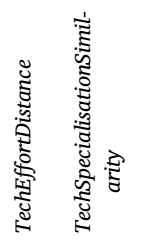

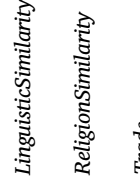

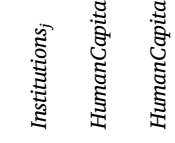

急 
Table A4

Inventors' top destinations (2000-2012).

\begin{tabular}{|c|c|c|c|}
\hline $\begin{array}{l}\text { Top Destination } \\
\text { Countries }\end{array}$ & $\begin{array}{l}\text { Origin of Largest } \\
\text { Flows }\end{array}$ & $\begin{array}{l}\text { Number of } \\
\text { Inventors }\end{array}$ & $\%$ out of total \\
\hline \multirow[t]{3}{*}{ USA } & & 95,735 & \\
\hline & UK & 17,424 & $18.20 \%$ \\
\hline & Germany & 12,040 & $12.58 \%$ \\
\hline \multirow[t]{3}{*}{ Germany } & & 22,453 & \\
\hline & Austria & 3169 & $14.11 \%$ \\
\hline & UK & 2429 & $10.82 \%$ \\
\hline \multirow[t]{4}{*}{ Switzerland } & & 22,198 & \\
\hline & Germany & 9719 & $43.78 \%$ \\
\hline & France & 3341 & $15.05 \%$ \\
\hline & Italy & 1824 & $8.22 \%$ \\
\hline \multirow[t]{3}{*}{ UK } & & 13,008 & \\
\hline & France & 2372 & $18.23 \%$ \\
\hline & Germany & 1917 & $14.74 \%$ \\
\hline \multirow[t]{4}{*}{ Nederlands } & & 8400 & \\
\hline & Germany & 2515 & $29.94 \%$ \\
\hline & UK & 1633 & $19.44 \%$ \\
\hline & Italy/France & 656 & $7.81 \%$ \\
\hline
\end{tabular}


Table A5

ZINB estimates of international inventor mobility (Sensitivity A) (dep. var.: Flows $s_{i j t}$ ).

\begin{tabular}{|c|c|c|c|c|c|c|c|c|}
\hline & \multicolumn{2}{|l|}{ (1) } & \multicolumn{2}{|l|}{ (2) } & \multicolumn{2}{|l|}{ (3) } & \multicolumn{2}{|l|}{ (4) } \\
\hline & NB & $\operatorname{logit}$ & NB & logit & NB & logit & NB & logit \\
\hline Neighbouring Countries $[>300 \mathrm{Km}]$ & $\begin{array}{l}-0.615^{* *} \\
(0.247)\end{array}$ & $\begin{array}{l}18.98^{* * *} \\
(1.986)\end{array}$ & $\begin{array}{l}-0.609 * * \\
(0.242)\end{array}$ & $\begin{array}{l}15.70^{* * *} \\
(1.098)\end{array}$ & $\begin{array}{l}-0.601^{* * *} \\
(0.215)\end{array}$ & $\begin{array}{l}16.27^{* * *} \\
(1.145)\end{array}$ & $\begin{array}{l}-0.595^{* * *} \\
(0.205)\end{array}$ & $\begin{array}{l}11.08^{* * *} \\
(1.771)\end{array}$ \\
\hline Distance $[<1110 \mathrm{Km}]$ & $\begin{array}{l}-1.469^{* * *} \\
(0.211)\end{array}$ & $\begin{array}{l}2.177 \\
(1.679)\end{array}$ & $\begin{array}{l}-1.442^{* * *} \\
(0.207)\end{array}$ & $\begin{array}{l}13.87^{* * *} \\
(1.087)\end{array}$ & $\begin{array}{l}-1.089^{* * *} \\
(0.207)\end{array}$ & $\begin{array}{l}14.45^{* * *} \\
(1.238)\end{array}$ & $\begin{array}{l}-0.946^{* * *} \\
(0.198)\end{array}$ & $\begin{array}{l}11.08^{* * *} \\
(1.315)\end{array}$ \\
\hline Distance $[1110-1500 \mathrm{Km}]$ & $\begin{array}{l}-1.670^{* * *} \\
(0.222)\end{array}$ & $\begin{array}{l}4.472 \\
(5.747)\end{array}$ & $\begin{array}{l}-1.654^{* * * *} \\
(0.217)\end{array}$ & $\begin{array}{l}13.74 * * * \\
(1.364)\end{array}$ & $\begin{array}{l}-1.253^{* * *} \\
(0.213)\end{array}$ & $\begin{array}{l}14.20^{* * *} \\
(1.742)\end{array}$ & $\begin{array}{l}-1.073^{* * *} \\
(0.206)\end{array}$ & $\begin{array}{l}11.26^{* * *} \\
(1.298)\end{array}$ \\
\hline Distance $[>1500 \mathrm{Km}]$ & $\begin{array}{l}-2.326^{* * *} \\
(0.237)\end{array}$ & $\begin{array}{l}19.32 \\
(12.34)\end{array}$ & $\begin{array}{l}-2.277^{* * * *} \\
(0.231)\end{array}$ & $\begin{array}{l}15.41^{* * *} \\
(0.714)\end{array}$ & $\begin{array}{l}-1.799^{* * * *} \\
(0.227)\end{array}$ & $\begin{array}{l}15.77^{* * *} \\
(1.048)\end{array}$ & $\begin{array}{l}-1.602^{* * * *} \\
(0.220)\end{array}$ & $\begin{array}{l}10.15^{* * *} \\
(1.488)\end{array}$ \\
\hline Density $_{i}$ & $\begin{array}{l}-0.037 \\
(0.051)\end{array}$ & $\begin{array}{l}0.015 \\
(0.035)\end{array}$ & $\begin{array}{l}-0.044 \\
(0.051)\end{array}$ & $\begin{array}{l}0.057^{* * *} \\
(0.016)\end{array}$ & $\begin{array}{l}-0.061 \\
(0.051)\end{array}$ & $\begin{array}{l}0.058^{* * *} \\
(0.015)\end{array}$ & $\begin{array}{l}-0.037 \\
(0.050)\end{array}$ & $\begin{array}{l}0.039 * * * \\
(0.013)\end{array}$ \\
\hline Density $_{j}$ & $\begin{array}{l}-0.075^{*} \\
(0.045)\end{array}$ & $\begin{array}{l}-0.156^{* * *} \\
(0.053)\end{array}$ & $\begin{array}{l}-0.076^{*} \\
(0.046)\end{array}$ & $\begin{array}{l}-0.080^{* * *} \\
(0.020)\end{array}$ & $\begin{array}{l}-0.080^{*} \\
(0.046)\end{array}$ & $\begin{array}{l}-0.074^{* * *} \\
(0.018)\end{array}$ & $\begin{array}{l}-0.084 * \\
(0.044)\end{array}$ & $\begin{array}{l}-0.092^{* * *} \\
(0.018)\end{array}$ \\
\hline lnInventors $_{i}$ & $\begin{array}{l}0.876^{* * *} \\
(0.068)\end{array}$ & $\begin{array}{l}-0.598^{* * *} \\
(0.137)\end{array}$ & $\begin{array}{l}0.840 * * * \\
(0.070)\end{array}$ & $\begin{array}{l}-0.311^{* *} \\
(0.125)\end{array}$ & $\begin{array}{l}0.821 * * * \\
(0.071)\end{array}$ & $\begin{array}{l}-0.332^{* * *} \\
(0.119)\end{array}$ & $\begin{array}{l}0.853^{* * *} \\
(0.071)\end{array}$ & $\begin{array}{l}-0.194 \\
(0.130)\end{array}$ \\
\hline InInventors $_{j}$ & $\begin{array}{l}0.177^{* * *} \\
(0.059)\end{array}$ & $\begin{array}{l}-0.893^{* *} \\
(0.383)\end{array}$ & $\begin{array}{l}0.231^{* * *} \\
(0.061)\end{array}$ & $\begin{array}{l}-0.677^{* * *} \\
(0.133)\end{array}$ & $\begin{array}{l}0.220^{* * *} \\
(0.059)\end{array}$ & $\begin{array}{l}-0.660^{* * *} \\
(0.119)\end{array}$ & $\begin{array}{l}0.250 * * * \\
(0.058)\end{array}$ & $\begin{array}{l}-0.414^{* * *} \\
(0.144)\end{array}$ \\
\hline TechEffortDistance & & & $\begin{array}{l}0.403^{* * *} \\
(0.115)\end{array}$ & $\begin{array}{l}-0.622^{* * * *} \\
(0.221)\end{array}$ & $\begin{array}{l}0.388^{* *} \\
(0.185)\end{array}$ & $\begin{array}{l}-0.637^{* * *} \\
(0.231)\end{array}$ & $\begin{array}{l}0.365^{* * *} \\
(0.112)\end{array}$ & $\begin{array}{l}-0.055 \\
(0.316)\end{array}$ \\
\hline TechSpecialisationSimilarity & & & $\begin{array}{l}0.590 * * \\
(0.294)\end{array}$ & $\begin{array}{l}-7.621^{* * *} \\
(1.637)\end{array}$ & $\begin{array}{l}0.578^{* * *} \\
(0.080)\end{array}$ & $\begin{array}{l}-6.981^{* * *} \\
(1.333)\end{array}$ & $\begin{array}{l}0.531 * * * \\
(0.191)\end{array}$ & $\begin{array}{l}-2.774^{* *} \\
(1.167)\end{array}$ \\
\hline LinguisticSimilarity & & & & & $\begin{array}{l}0.294^{* * *} \\
(0.073)\end{array}$ & $\begin{array}{l}-12.99^{* * *} \\
(1.943)\end{array}$ & $\begin{array}{l}0.265^{* * *} \\
(0.089)\end{array}$ & $\begin{array}{l}-0.170 \\
(0.736)\end{array}$ \\
\hline ReligionSimilarity & & & & & $\begin{array}{l}0.305^{* * *} \\
(0.010)\end{array}$ & $\begin{array}{l}-0.454 \\
(1.353)\end{array}$ & $\begin{array}{l}0.298 * * * \\
(0.096)\end{array}$ & $\begin{array}{c}-0.892 \\
(0.987)\end{array}$ \\
\hline Trade $_{i j}$ & & & & & & & $\begin{array}{l}0.330 * * \\
(0.155)\end{array}$ & $\begin{array}{l}-19.3^{* *} \\
(8.415)\end{array}$ \\
\hline Institutions $_{i}$ & & & & & & & $\begin{array}{l}0.199 * \\
(0.111)\end{array}$ & $\begin{array}{l}-2.262^{* * *} \\
(0.489)\end{array}$ \\
\hline Institutions $_{j}$ & & & & & & & $\begin{array}{l}0.016 \\
(0.110)\end{array}$ & $\begin{array}{l}0.416 \\
(0.669)\end{array}$ \\
\hline HumanCapital $_{i}$ & & & & & & & $\begin{array}{l}0.023 \\
(0.114)\end{array}$ & $\begin{array}{l}0.855^{* *} \\
(0.392)\end{array}$ \\
\hline HumanCapital $_{j}$ & & & & & & & $\begin{array}{l}0.099 \\
(0.115)\end{array}$ & $\begin{array}{c}-0.056 \\
(0.458)\end{array}$ \\
\hline Observations & 11,310 & 11,310 & 11,310 & 11,310 & 11,310 & 11,310 & 11,310 & 11,310 \\
\hline Nonzero observations & 5056 & 5056 & 5056 & 5056 & 5056 & 5056 & 5056 & 5056 \\
\hline LR test for overdispresion & 36,000 & & 35,000 & & 28,000 & & 28,000 & \\
\hline p-value & 0.000 & & 0.000 & & 0.000 & & 0.000 & \\
\hline Vuong statistic & 3.89 & & 5.93 & & 6.34 & & 8.80 & \\
\hline p-value & 0.000 & & 0.000 & & 0.000 & & 0.000 & \\
\hline McFadden's $R^{2}$ & 0.300 & & 0.303 & & 0.308 & & 0.313 & \\
\hline
\end{tabular}

All regressions include origin and destination country and year fixed effects; Coefficients of constant term are omitted for brevity; All regressors are one period lagged; Robust standard errors in parentheses; $(* * *): p<0.01,(* *): p<0.05,(*): p<0.1$ significance at $1 \%, 5 \%$ and $10 \%$, respectively. Overdispersion LR tests largely reject the null hypothesis of no overdispersion. Vuong statistic favors the hypothesis of zero-inflated model. The set of covariates in the logit specifications that predict the probability of belonging to the strictly-zero mobility group are the same regressors as in the negative binomial model. 
Table A6

ZINB estimates of international inventor mobility (Sensitivity B) (dep. var.: Flows $s_{i j t}$ ) .

\begin{tabular}{|c|c|c|c|c|c|c|c|c|}
\hline & \multicolumn{2}{|l|}{ (1) } & \multicolumn{2}{|l|}{ (2) } & \multicolumn{2}{|l|}{ (3) } & \multicolumn{2}{|l|}{ (4) } \\
\hline & NB & logit & NB & logit & NB & logit & NB & logit \\
\hline Neighbouring Countries $[>300 \mathrm{Km}]$ & $\begin{array}{l}-0.533^{* * *} \\
(0.190)\end{array}$ & $\begin{array}{l}4.962 \\
(9.191)\end{array}$ & $\begin{array}{l}-0.535^{* * *} \\
(0.195)\end{array}$ & $\begin{array}{l}6.906 \\
(94.42)\end{array}$ & $\begin{array}{l}-0.619 * * * \\
(0.203)\end{array}$ & $\begin{array}{l}-4.061 \\
(2.523)\end{array}$ & $\begin{array}{l}-0.537^{* *} \\
(0.210)\end{array}$ & $\begin{array}{l}11.94 * * * \\
(1.631)\end{array}$ \\
\hline Distance $[<1110 \mathrm{Km}]$ & $\begin{array}{l}-0.851^{* * *} \\
(0.196)\end{array}$ & $\begin{array}{l}6.617 \\
(8.653)\end{array}$ & $\begin{array}{l}-0.834^{* * *} \\
(0.188)\end{array}$ & $\begin{array}{l}8.514 \\
(94.42)\end{array}$ & $\begin{array}{l}-1.001^{* * *} \\
(0.199)\end{array}$ & $\begin{array}{l}11.03^{* * *} \\
(1.648)\end{array}$ & $\begin{array}{l}-0.893^{* * *} \\
(0.206)\end{array}$ & $\begin{array}{l}11.06^{* * *} \\
(1.460)\end{array}$ \\
\hline Distance $[1110-1500 \mathrm{Km}]$ & $\begin{array}{l}-0.972^{* * *} \\
(0.204)\end{array}$ & $\begin{array}{l}7.303 \\
(9.906)\end{array}$ & $\begin{array}{l}-0.958^{* * *} \\
(0.207)\end{array}$ & $\begin{array}{l}8.900 \\
(94.81)\end{array}$ & $\begin{array}{l}-1.057^{* * *} \\
(0.206)\end{array}$ & $\begin{array}{l}11.36 * * * \\
(1.478)\end{array}$ & $\begin{array}{l}-1.036^{* * *} \\
(0.211)\end{array}$ & $\begin{array}{l}11.30 * * * \\
(1.446)\end{array}$ \\
\hline Distance $[>1500 \mathrm{Km}]$ & $\begin{array}{l}-1.108^{* * *} \\
(0.242)\end{array}$ & $\begin{array}{l}7.160 \\
(9.747)\end{array}$ & $\begin{array}{l}-1.114^{* * *} \\
(0.230)\end{array}$ & $\begin{array}{l}8.797 \\
(94.75)\end{array}$ & $\begin{array}{l}-1.619^{* * *} \\
(0.224)\end{array}$ & $\begin{array}{l}10.76^{* * *} \\
(1.724)\end{array}$ & $\begin{array}{l}-1.527^{* * *} \\
(0.226)\end{array}$ & $\begin{array}{l}10.25^{* * *} \\
(1.534)\end{array}$ \\
\hline Density $_{i}$ & $\begin{array}{l}-0.070 \\
(0.070)\end{array}$ & $\begin{array}{l}-0.032 \\
(0.037)\end{array}$ & $\begin{array}{l}-0.079 \\
(0.078)\end{array}$ & $\begin{array}{l}-0.025 \\
(0.044)\end{array}$ & $\begin{array}{l}-0.106^{*} \\
(0.055)\end{array}$ & $\begin{array}{l}0.032^{*} \\
(0.017)\end{array}$ & $\begin{array}{l}-0.050 \\
(0.050)\end{array}$ & $\begin{array}{l}0.038^{* * *} \\
(0.012)\end{array}$ \\
\hline Density $_{j}$ & $\begin{array}{l}-0.083 \\
(0.069)\end{array}$ & $\begin{array}{l}-0.044 \\
(0.036)\end{array}$ & $\begin{array}{l}0.021 \\
(0.071)\end{array}$ & $\begin{array}{l}-0.033 \\
(0.033)\end{array}$ & $\begin{array}{l}-0.070 \\
(0.046)\end{array}$ & $\begin{array}{l}-0.075^{* * *} \\
(0.019)\end{array}$ & $\begin{array}{l}-0.095^{* *} \\
(0.044)\end{array}$ & $\begin{array}{l}0.087 * * * \\
(0.017)\end{array}$ \\
\hline lnInventors $_{i}$ & $\begin{array}{l}0.858^{* * *} \\
(0.106)\end{array}$ & $\begin{array}{l}-0.084 \\
(0.164)\end{array}$ & $\begin{array}{l}0.868^{* * *} \\
(0.108)\end{array}$ & $\begin{array}{l}-0.134 \\
(0.143)\end{array}$ & $\begin{array}{l}0.873^{* * *} \\
(0.075)\end{array}$ & $\begin{array}{l}-0.291 \\
(0.251)\end{array}$ & $\begin{array}{l}0.846^{* * *} \\
(0.071)\end{array}$ & $\begin{array}{l}(0.114) \\
-0.445^{* * *}\end{array}$ \\
\hline lnInventors $_{j}$ & $\begin{array}{l}0.198 * * * \\
(0.080)\end{array}$ & $\begin{array}{l}-0.826^{* * *} \\
(0.155)\end{array}$ & $\begin{array}{l}0.147 \\
(0.091)\end{array}$ & $\begin{array}{l}-0.629 * * * \\
(0.182)\end{array}$ & $\begin{array}{l}0.278^{* * * *} \\
(0.064)\end{array}$ & $\begin{array}{l}-0.310 \\
(0.235)\end{array}$ & $\begin{array}{l}0.238^{* * *} \\
(0.056)\end{array}$ & $\begin{array}{l}(0.130) \\
-0.363\end{array}$ \\
\hline TechEffortDistance & $\begin{array}{l}0.139 * * * \\
(0.007)\end{array}$ & $\begin{array}{l}-0.738^{*} \\
(0.430)\end{array}$ & $\begin{array}{l}0.248^{* * *} \\
(0.017)\end{array}$ & $\begin{array}{l}-0.671^{*} \\
(0.396)\end{array}$ & $\begin{array}{l}0.434 * * * \\
(0.122)\end{array}$ & $\begin{array}{l}-0.327 \\
(0.535)\end{array}$ & $\begin{array}{l}0.365^{* * *} \\
(0.111)\end{array}$ & $\begin{array}{l}-0.363 \\
(0.242)\end{array}$ \\
\hline TechSpecialisationSimilarity & $\begin{array}{l}0.527^{* *} \\
(0.160)\end{array}$ & $\begin{array}{l}-1.052 \\
(1.979)\end{array}$ & $\begin{array}{l}0.559^{* *} \\
(0.282)\end{array}$ & $\begin{array}{l}-0.552 \\
(1.926)\end{array}$ & $\begin{array}{l}0.520^{* * *} \\
(0.260)\end{array}$ & $\begin{array}{l}-2.194 \\
(1.480)\end{array}$ & $\begin{array}{l}0.500^{*} \\
(0.279)\end{array}$ & $\begin{array}{l}-2.172^{* *} \\
(0.938)\end{array}$ \\
\hline LinguisticSimilarity & $\begin{array}{l}0.315^{* * *} \\
(0.048)\end{array}$ & $\begin{array}{l}-6.500 \\
(6.409)\end{array}$ & $\begin{array}{l}0.337^{* * * *} \\
(0.058)\end{array}$ & $\begin{array}{l}0.423 \\
(2.624)\end{array}$ & $\begin{array}{l}0.348^{* * * *} \\
(0.113)\end{array}$ & $\begin{array}{l}0.415 \\
(0.850)\end{array}$ & $\begin{array}{l}0.458^{* * * *} \\
(0.112)\end{array}$ & $\begin{array}{l}0.001 \\
(0.902)\end{array}$ \\
\hline ReligionSimilarity & $\begin{array}{l}0.363^{* * *} \\
(0.029)\end{array}$ & $\begin{array}{l}0.192 \\
(0.635)\end{array}$ & $\begin{array}{l}0.322^{* * *} \\
(0.024)\end{array}$ & $\begin{array}{l}-0.384 \\
(0.821)\end{array}$ & $\begin{array}{l}0.413^{* * * *} \\
(0.019)\end{array}$ & $\begin{array}{l}-1.862 \\
(1.395)\end{array}$ & $\begin{array}{l}0.427^{* *} \\
(0.205)\end{array}$ & $\begin{array}{l}-1.171 \\
(1.018)\end{array}$ \\
\hline Trade $_{i j}$ & $\begin{array}{l}0.335^{* * *} \\
(0.006)\end{array}$ & $\begin{array}{l}-3.169 \\
(2.386)\end{array}$ & $\begin{array}{l}0.417^{* * *} \\
(0.016)\end{array}$ & $\begin{array}{l}-0.696 \\
(1.969)\end{array}$ & $\begin{array}{l}0.390^{* *} \\
(0.162)\end{array}$ & $\begin{array}{l}-167.9^{*} \\
(100.5)\end{array}$ & $\begin{array}{l}0.369 * * \\
(0.289)\end{array}$ & $\begin{array}{l}-157.6^{*} \\
(89.56)\end{array}$ \\
\hline Institutions $_{i}$ & $\begin{array}{l}0.121 \\
(0.282)\end{array}$ & $\begin{array}{l}-1.351^{* * *} \\
(0.380)\end{array}$ & $\begin{array}{l}0.143 \\
(0.335)\end{array}$ & $\begin{array}{l}-0.672 \\
(0.729)\end{array}$ & $\begin{array}{l}0.092 \\
(0.198)\end{array}$ & $\begin{array}{l}-2.462^{* * *} \\
(0.592)\end{array}$ & $\begin{array}{l}0.178 \\
(0.111)\end{array}$ & $\begin{array}{l}-3.061^{* * *} \\
(0.517)\end{array}$ \\
\hline Institutions $_{j}$ & $\begin{array}{l}-0.080 \\
(0.230)\end{array}$ & $\begin{array}{l}-0.102 \\
(1.391)\end{array}$ & $\begin{array}{l}-0.117 \\
(0.251)\end{array}$ & $\begin{array}{l}-0.305 \\
(0.458)\end{array}$ & $\begin{array}{l}-0.152 \\
(0.161)\end{array}$ & $\begin{array}{l}-0.135 \\
(0.645)\end{array}$ & $\begin{array}{l}0.232 \\
(0.211)\end{array}$ & $\begin{array}{l}-0.385 \\
(0.662)\end{array}$ \\
\hline HumanCapital $_{i}$ & $\begin{array}{l}0.008 \\
(0.007)\end{array}$ & $\begin{array}{l}0.065 \\
(0.052)\end{array}$ & $\begin{array}{l}0.025^{* *} \\
(0.012)\end{array}$ & $\begin{array}{l}0.021 \\
(0.042)\end{array}$ & $\begin{array}{l}0.012 \\
(0.118)\end{array}$ & $\begin{array}{l}0.033 \\
(0.541)\end{array}$ & $\begin{array}{l}0.046 \\
(0.114)\end{array}$ & $\begin{array}{l}0.801 * * \\
(0.341)\end{array}$ \\
\hline HumanCapital $_{j}$ & $\begin{array}{l}0.005 \\
(0.006)\end{array}$ & $\begin{array}{l}0.124 \\
(0.090)\end{array}$ & $\begin{array}{l}0.035^{* * *} \\
(0.012)\end{array}$ & $\begin{array}{l}0.045 \\
(0.066)\end{array}$ & $\begin{array}{l}0.011 \\
(0.111)\end{array}$ & $\begin{array}{l}0.228 \\
(0.859)\end{array}$ & $\begin{array}{l}0.090 \\
(0.112)\end{array}$ & $\begin{array}{l}0.197 \\
(0.380)\end{array}$ \\
\hline$E P L_{i}$ & & & & & $\begin{array}{l}0.114^{*} \\
(0.060)\end{array}$ & $\begin{array}{l}0.509 \\
(0.409)\end{array}$ & & \\
\hline$E P L_{j}$ & & & & & $\begin{array}{l}-0.186 \\
(0.208)\end{array}$ & $\begin{array}{l}0.084 \\
(0.537)\end{array}$ & & \\
\hline Dummy $y_{\text {Schengen }}$ & & & & & & & $\begin{array}{l}0.171 \\
(0.105)\end{array}$ & $\begin{array}{l}0.467 \\
(0.387)\end{array}$ \\
\hline Dummy $_{\text {Eurozone }}$ & & & & & & & $\begin{array}{l}0.176^{* *} \\
(0.078)\end{array}$ & $\begin{array}{l}-0.909 * \\
(0.518)\end{array}$ \\
\hline Observations & 6106 & 6106 & 5200 & 5200 & 7718 & 7718 & 11,310 & 11,310 \\
\hline Nonzero observations & 2609 & 2609 & 2252 & 2252 & 4536 & 4536 & 5056 & 5,056 \\
\hline LR test for overdispresion & 9501 & & 8047 & & 22,100 & & 27,080 & \\
\hline p-value & 0.000 & & 0.000 & & 0.000 & & 0.000 & \\
\hline Vuong statistic & 4.57 & & 3.92 & & 7.95 & & 9.29 & \\
\hline p-value & 0.000 & & 0.000 & & 0.000 & & 0.000 & \\
\hline McFadden's $R^{2}$ & 0.326 & & 0.325 & & 0.282 & & 0.315 & \\
\hline
\end{tabular}

All regressions include origin and destination country and year fixed effects; All regressors are one period lagged; Coefficients of constant terms are omitted for brevity; Robust standard errors in parentheses; $\left(^{* * *}\right): \mathrm{p}<0.01,(* *): \mathrm{p}<0.05,(*): \mathrm{p}<0.1$ significance at $1 \%, 5 \%$ and $10 \%$, respectively. Columns (1) and (2) report estimates of HumanCapital proxied by STEM and HRST, respectively. Column (3) includes an additional institutional variable, the stringency of the employment protection legislation, EPL. Column (4) includes dummies for Eurozone and Schengen membership: Dummy is one if both countries are Eurozone (Schengen) members and 0 otherwise. 
Table A7

Top destination and origin countries of non-inventor migrant flows.

\begin{tabular}{llll}
\hline $\begin{array}{l}\text { Top Destination } \\
\text { Countries }\end{array}$ & $\begin{array}{l}\text { Origin of Major } \\
\text { Flows }\end{array}$ & $\begin{array}{l}\text { Number of } \\
\text { migrants }\end{array}$ & Share \\
\hline Germany & & $3,540,019$ & $44.56 \%$ \\
& Poland & $1,577,493$ & $8.48 \%$ \\
& Italy & 300,308 & $7.88 \%$ \\
UK & Hungary & 278,914 & $17.23 \%$ \\
& & $1,313,663$ & $15.38 \%$ \\
& Poland & 226,361 & $12.99 \%$ \\
USA & USA & 202,022 & $23.73 \%$ \\
& Germany & 170,656 & $17.74 \%$ \\
& Republic of Korea & $1,183,853$ & $16.08 \%$ \\
Spain & Canada & 280,900 & $31.31 \%$ \\
& UK & 209,969 & $17.08 \%$ \\
& & 190,316 & $15.79 \%$ \\
Japan & UK & 962,090 & 300,198 \\
& Italy & 164,289 & $3.75 \%$ \\
& Germany & 151,954 & $30.51 \%$ \\
& Republic of Korea & 938,482 & $8.49 \%$ \\
\hline
\end{tabular}


Table A8

2SRI estimates of international inventors' mobility (Robustness) (dep. var.: Flows $s_{i j t}$ ).

\begin{tabular}{|c|c|c|c|c|c|c|c|}
\hline & (a) & (b) & (c) & (d) & (e) & (f) & $(g)$ \\
\hline Neighbouring Countries $[>300 \mathrm{Km}]$ & $\begin{array}{l}-0.595^{* * *} \\
(0.205)\end{array}$ & $\begin{array}{l}-0.629 * * * \\
(0.194)\end{array}$ & $\begin{array}{l}-0.612^{* * *} \\
(0.194)\end{array}$ & $\begin{array}{l}-0.614^{* * *} \\
(0.195)\end{array}$ & $\begin{array}{l}-0.620^{* * *} \\
(0.214)\end{array}$ & $\begin{array}{l}-0.604^{* * *} \\
(0.201)\end{array}$ & $\begin{array}{l}-0.601 * * * \\
(0.201)\end{array}$ \\
\hline Distance $[<1110 \mathrm{Km}]$ & $\begin{array}{l}-0.946 * * * \\
(0.198)\end{array}$ & $\begin{array}{l}-0.927 * * * \\
(0.192)\end{array}$ & $\begin{array}{l}-0.935^{* * *} \\
(0.190)\end{array}$ & $\begin{array}{l}-0.950^{* * *} \\
(0.191)\end{array}$ & $\begin{array}{l}-0.946 * * * \\
(0.195)\end{array}$ & $\begin{array}{l}-0.946^{* * *} \\
(0.195)\end{array}$ & $\begin{array}{l}-0.944^{* * * *} \\
(0.195)\end{array}$ \\
\hline Distance $[1110-1500 \mathrm{Km}]$ & $\begin{array}{l}-1.073^{* * *} \\
(0.206)\end{array}$ & $\begin{array}{l}-1.012^{* * *} \\
(0.199)\end{array}$ & $\begin{array}{l}-1.005^{* * *} \\
(0.198)\end{array}$ & $\begin{array}{l}-1.004^{* * *} \\
(0.199)\end{array}$ & $\begin{array}{l}-1.078^{* * *} \\
(0.206)\end{array}$ & $\begin{array}{l}-1.072^{* * *} \\
(0.203)\end{array}$ & $\begin{array}{l}-1.069^{* * * *} \\
(0.203)\end{array}$ \\
\hline Distance $[>1500 K m]$ & $\begin{array}{l}-1.602^{* * * *} \\
(0.220)\end{array}$ & $\begin{array}{l}-1.483^{* * *} \\
(0.216)\end{array}$ & $\begin{array}{l}-1.490^{* * *} \\
(0.215)\end{array}$ & $\begin{array}{l}-1.494^{* * *} \\
(0.216)\end{array}$ & $\begin{array}{l}-1.602^{* * *} \\
(0.219)\end{array}$ & $\begin{array}{l}-1.598^{* * *} \\
(0.216)\end{array}$ & $\begin{array}{l}-1.598^{* * *} \\
(0.216)\end{array}$ \\
\hline Density $_{i}$ & $\begin{array}{l}-0.037 \\
(0.050)\end{array}$ & $\begin{array}{l}-0.044 \\
(0.050)\end{array}$ & $\begin{array}{l}-0.023 \\
(0.052)\end{array}$ & $\begin{array}{l}-0.018 \\
(0.055)\end{array}$ & $\begin{array}{l}-0.042 \\
(0.050)\end{array}$ & $\begin{array}{l}-0.045 \\
(0.049)\end{array}$ & $\begin{array}{l}-0.049 \\
(0.050)\end{array}$ \\
\hline Density $_{j}$ & $\begin{array}{l}-0.084^{* * *} \\
(0.044)\end{array}$ & $\begin{array}{l}-0.121^{* * *} \\
(0.046)\end{array}$ & $\begin{array}{l}-0.133^{* * *} \\
(0.049)\end{array}$ & $\begin{array}{l}-0.086^{*} \\
(0.051)\end{array}$ & $\begin{array}{l}-0.103^{* *} \\
(0.044)\end{array}$ & $\begin{array}{l}-0.101^{* *} \\
(0.044)\end{array}$ & $\begin{array}{l}-0.090^{* *} \\
(0.045)\end{array}$ \\
\hline lnInventors $_{i}$ & $\begin{array}{l}0.853^{* * *} \\
(0.071)\end{array}$ & $\begin{array}{l}0.853^{* * *} \\
(0.070)\end{array}$ & $\begin{array}{l}0.952^{* * *} \\
(0.074)\end{array}$ & $\begin{array}{l}1.041^{* * * *} \\
(0.084)\end{array}$ & $\begin{array}{l}0.869^{* * *} \\
(0.111)\end{array}$ & $\begin{array}{l}0.850^{* * *} \\
(0.071)\end{array}$ & $\begin{array}{l}0.852^{* * *} \\
(0.071)\end{array}$ \\
\hline lnInventors $_{j}$ & $\begin{array}{l}0.250 * * * \\
(0.058)\end{array}$ & $\begin{array}{l}0.185^{* * *} \\
(0.057)\end{array}$ & $\begin{array}{l}0.170 * * * \\
(0.062)\end{array}$ & $\begin{array}{l}0.218^{* * *} \\
(0.067)\end{array}$ & $\begin{array}{l}0.238^{* * *} \\
(0.060)\end{array}$ & $\begin{array}{l}0.253^{* * *} \\
(0.057)\end{array}$ & $\begin{array}{l}0.246^{* * *} \\
(0.057)\end{array}$ \\
\hline TechEffortDistance & $\begin{array}{l}0.365^{* * *} \\
(0.112)\end{array}$ & $\begin{array}{l}0.352^{* * *} \\
(0.107)\end{array}$ & $\begin{array}{l}0.359 * * * \\
(0.103)\end{array}$ & $\begin{array}{l}0.315^{* *} \\
(0.108)\end{array}$ & $\begin{array}{l}0.334^{* * *} \\
(0.108)\end{array}$ & $\begin{array}{l}0.363^{* * *} \\
(0.103)\end{array}$ & $\begin{array}{l}0.357 * * * \\
(0.109)\end{array}$ \\
\hline TechSpecialisationSimilarity & $\begin{array}{l}0.531 * * * \\
(0.191)\end{array}$ & $\begin{array}{l}0.535 * * \\
(0.271)\end{array}$ & $\begin{array}{l}0.538^{* *} \\
(0.269)\end{array}$ & $\begin{array}{l}0.541^{* *} \\
(0.276)\end{array}$ & $\begin{array}{l}0.533^{* *} \\
(0.268)\end{array}$ & $\begin{array}{l}0.536 * * \\
(0.270)\end{array}$ & $\begin{array}{l}0.542^{* *} \\
(0.164)\end{array}$ \\
\hline LinguisticSimilarity & $\begin{array}{l}0.265^{* * *} \\
(0.089)\end{array}$ & $\begin{array}{l}0.261^{* * * *} \\
(0.090)\end{array}$ & $\begin{array}{l}0.263^{* *} \\
(0.018)\end{array}$ & $\begin{array}{l}0.258 * * * \\
(0.009)\end{array}$ & $\begin{array}{l}0.255^{* * *} \\
(0.016)\end{array}$ & $\begin{array}{l}0.261 * * * \\
(0.082)\end{array}$ & $\begin{array}{l}0.262^{* * *} \\
(0.091)\end{array}$ \\
\hline ReligionSimilarity & $\begin{array}{l}0.298^{* * *} \\
(0.096)\end{array}$ & $\begin{array}{l}0.281^{* * *} \\
(0.063)\end{array}$ & $\begin{array}{l}0.282^{* * *} \\
(0.071)\end{array}$ & $\begin{array}{l}0.286 * * * \\
(0.068)\end{array}$ & $\begin{array}{l}0.271^{* * *} \\
(0.069)\end{array}$ & $\begin{array}{l}0.277^{* * *} \\
(0.086)\end{array}$ & $\begin{array}{l}0.275^{* * *} \\
(0.054)\end{array}$ \\
\hline Trade $_{i j}$ & $\begin{array}{l}0.330 * * \\
(0.151)\end{array}$ & $\begin{array}{l}0.331^{* *} \\
(0.164)\end{array}$ & $\begin{array}{l}0.325^{* *} \\
(0.156)\end{array}$ & $\begin{array}{l}0.333^{* *} \\
(0.161)\end{array}$ & $\begin{array}{l}0.255^{* *} \\
(0.130)\end{array}$ & $\begin{array}{l}0.249 * * \\
(0.121)\end{array}$ & $\begin{array}{l}0.235^{* *} \\
(0.112)\end{array}$ \\
\hline Institutions $_{i}$ & $\begin{array}{l}0.199 * \\
(0.111)\end{array}$ & $\begin{array}{l}0.225^{* *} \\
(0.112)\end{array}$ & $\begin{array}{l}0.236^{* *} \\
(0.119)\end{array}$ & $\begin{array}{l}0.286^{* *} \\
(0.140)\end{array}$ & $\begin{array}{l}0.275^{* *} \\
(0.116)\end{array}$ & $\begin{array}{l}0.225^{* *} \\
(0.114)\end{array}$ & $\begin{array}{l}0.272^{* *} \\
(0.118)\end{array}$ \\
\hline Institutions $_{j}$ & $\begin{array}{l}0.016 \\
(0.110)\end{array}$ & $\begin{array}{l}-0.066 \\
(0.115)\end{array}$ & $\begin{array}{l}-0.064 \\
(0.119)\end{array}$ & $\begin{array}{l}-0.132 \\
(0.136)\end{array}$ & $\begin{array}{l}-0.012 \\
(0.117)\end{array}$ & $\begin{array}{l}0.007 \\
(0.110)\end{array}$ & $\begin{array}{c}-0.017 \\
(0.113)\end{array}$ \\
\hline HumanCapital $_{i}$ & $\begin{array}{l}0.023 \\
(0.114)\end{array}$ & $\begin{array}{l}0.111 \\
(0.118)\end{array}$ & $\begin{array}{l}0.098 \\
(0.125)\end{array}$ & $\begin{array}{l}0.132 \\
(0.130)\end{array}$ & $\begin{array}{l}0.049 \\
(0.131)\end{array}$ & $\begin{array}{l}0.024 \\
(0.114)\end{array}$ & $\begin{array}{l}0.023 \\
(0.114)\end{array}$ \\
\hline HumanCapital $_{j}$ & $\begin{array}{l}0.099 \\
(0.115)\end{array}$ & $\begin{array}{l}0.091 \\
(0.115)\end{array}$ & $\begin{array}{l}0.125 \\
(0.118)\end{array}$ & $\begin{array}{l}0.121 \\
(0.121)\end{array}$ & $\begin{array}{l}0.074 \\
(0.111)\end{array}$ & $\begin{array}{l}0.092 \\
(0.112)\end{array}$ & $\begin{array}{l}0.107 \\
(0.113)\end{array}$ \\
\hline Flows $_{i j} t-1$ & & $\begin{array}{l}0.001 * * \\
(0.0004)\end{array}$ & & & & & \\
\hline Flows $_{i j} t-2$ & & & $\begin{array}{l}0.001 * * \\
(0.0004)\end{array}$ & & & & \\
\hline Flows $_{i j t-3}$ & & & & $\begin{array}{l}0.001 * * \\
(0.0004)\end{array}$ & & & \\
\hline Control term & & & & & $\begin{array}{l}-0.036 \\
(0.084)\end{array}$ & $\begin{array}{l}-0.126 \\
(0.092)\end{array}$ & $\begin{array}{l}-0.143 \\
(0.104)\end{array}$ \\
\hline Observations & 11,310 & 10,440 & 9570 & 8700 & 11,310 & 11,310 & 11,310 \\
\hline$F$-statistic (first stage) & & & & & 23.65 & 27.03 & 28.41 \\
\hline Hansen $J$ statistic & & & & & 52.876 & 55.408 & 57.321 \\
\hline p-value & & & & & 0.610 & 0.721 & 0.743 \\
\hline
\end{tabular}

All regressions include origin and destination country and year fixed effects; Coefficients of constant terms are omitted for brevity; All regressors are one period lagged; Robust standard errors in parentheses; Hansen $J$ statistic (p-value) tests the joint null hypothesis is that the instruments used are valid instruments; (***): $\mathrm{p}<0.01,(* *): p<0.05,(*): p<0.1$ significance at $1 \%, 5 \%$ and $10 \%$, respectively. Column (a) reports estimates of the original specification, without controlling for endogeneity, for comparison purposes; Columns (b) to (d) include lagged values of the dependent variable as instruments; Column (e) instruments for inventors (InInventors) at the host country (instruments: stock of foreigners and rule of law); Column (f) instruments for technological effort distance (TechEffortDistance) (instruments: stock of foreigners, rule of law, and number of universities per capita at the host country); and Column (g) instruments technological production structure similarity (TechSpecialisationSimilarity) (instruments: stock of foreigners, rule of law, and number of universities per capita at the host country).

\section{Supplementary material}

Supplementary material associated with this article can be found, in the online version, at10.1016/j.techfore.2020.120144 .

\section{References}

Acemoglu, D., Johnson, S., Robinson, J.A., 2005. Institutions as a fundamental cause of long-run growth. In: Aghion, P., Durlauf, S. (Eds.), Handbook of Economic Growth. North Holland, Amsterdam, pp. 384-473.

Aghion, P., Boustan, L., Hoxby, C., Vandenbussche, J., 2009. The Causal Impact of Education on Economic Growth: Evidence from U.S.The Causal Impact of Education on Economic Growth: Evidence from U.S. University of Harvard, Department of Economics, Working Paper

Aghion, P., Howitt, P., 1998. Endogenous Growth Theory. MIT Press, Massachusetts, USA.
Agrawal, A., Kapur, D., McHale, J., Oettl, A., 2011. Brain drain or brain bank? The impact of skilled emigration on poor-country innovation. J. Urban Econ. 69(1), 43-55.

Akcigit, U., Baslandze, S., Stantcheva, S., 2016. Taxation and the international mobility of inventors. Am. Econ. Rev. 106(10), 2930-2981.

Akcigit, U., Grigsby, J., Nicholas, T., 2017. Immigration and the Rise of American Ingenuity. NBER Working Paper 23137

Akcigit, U., Grigsby, J., Nicholas, T., 2017. The rise of American Ingenuity: Innovation and Inventors of the Golden Age. NBER Working Paper No. 23047

Alcacer, J., Gittelman, M., 2006. Patent citations as a measure of knowledge flows: the influence of examiner citations. Rev. Econ. Stat. 88(4), 774-779.

Anderson, J.E., van Wincoop, E., 2003. Gravity with gravitas: a solution to the border 
puzzle. Am. Econ. Rev. 93(1), 170-192.

Anjonami, A., Hariri, V., 1992. Migration stock and the issue of competing and complementary flows in United States interstate migration. J. Popul. Econ. 5(2), 87-100.

Beck, B., Moore, L., 1985. Linking the host culture to organizational variables. Organizational Culture. Sage, Beverly Hills, CA, pp. 335-354.

Beine, M., Docquier, F., Ožden, C., 2011. Diasporas. J. Econ. Dev. 95(1), 30-41.

Belenzon, S., Schankerman, M., 2013. Spreading the word: geography, policy and knowledge spillovers. Rev. Econ. Stat. 95(3), 884-903.

Benhabib, J., Spiegel, M.M., 1994. The role of human capital in economic development: evidence from aggregate cross-country data. J. Monet. Econ. 34(2), 143-173.

Bertoli, S., Moraga, J.F.-H., 2015. The size of the cliff at the border. Reg. Sci. Urban Econ. 51, 1-6.

Bode, E., 2004. The spatial pattern of localized R\&D spillovers: an empirical investigation for germany. J. Econ. Geogr. 4(1), 43-64.

Bottazzi, L., Peri, G., 2007. The international dynamics of R\&D and innovation in the long run and in the short run. Econ. J. 117(518), 486-511.

Branstetter, L.G., 2001. Are knowledge spillovers international or intranational in scope?: microeconometric evidence from the U.S. and Japan. J. Int. Econ. 53(1), 53-79.

Breschi, S., Lissoni, F., 2009. Knowledge networks from patent data: methodological is sues and research targets. J. Econ. Geogr. 9(2), 439-468.

Breschi, S., Lissoni, F., Miguelez, E., 2017. Migrant inventors in the US: testing for diaspora and brain gain effects. J. Econ. Geogr. 17(5), 1009-1038.

Burger, M., van Oort, F., Linders, G., 2009. On the specification of the gravity model of trade: zeros, excess zeros and zero-inflated estimation. Spat. Econ. Anal. 4(2), $167-190$.

Busenitz, L.W., Gómez, C., Spencer, J.W., 2000. Country institutional profiles: unlocking entrepreneurial phenomena. Acad. Manag. J. 43(5), 994-1003.

Cairncross, F., 1997. The Death of Distance: How Communications Revolution Will Change Our Lives. Orion Business Books, London.

Cameron, C.A., Trivedi, P.K., 2013. Regression Analysis of Count Data, second ed, Econometric Society Monograph No. 53 Cambridge University Press, 1998.

Caselli, F., Coleman, J.W., 2001. Cross-country technology diffusion: the case of computers. Am. Econ. Rev. 91(2), 328-335.

Caselli, F., Wilson, D., 2004. Importing technology. J. Monet. Econ. 51(1), 1-32.

Chen, N., 2004. Intra-national versus international trade in the european union: why do national borders matter? J. Int. Econ. 63(1), 93-118.

Coe, D., Helpman, E., 1995. International R\&D spillovers. Eur. Econ. Rev. 39(5), 859-887.

Crescenzi, R., Gagliardi, L., 2015. Moving People with Ideas Innovation, Inter-Regional Mobility and Firm Heterogeneity. SERC Discussion Paper 174

Czaika, M., Parsons, C., 2015. The Gravity of High Skilled Migration Policies. IMI Working Paper No. 110

De Beer, J., Raymer, J., van der Erf, R., van Wissen, L., 2010. Overcoming the problems of inconsistent international migration data: a new method applied to flows in europe. Eur. J. Popul. 26(4), 459-481.

De Groot, H., Linders, G.-J., Rietveld, P., Subramanian, U., 2004. The institutional determinants of bilateral trade patterns. Kyklos 57(1), 103-123.

Drivas, K., Economidou, C., Karkalakos, S., Tsionas, E.G., 2016. Mobility of knowledge and local innovation activity. Eur. Econ. Rev. 85(C), 39-61.

Eaton, J., Kortum, S., 1999. International technology diffusion: theory and measurement. Int. Econ. Rev. 40, 53770.

Eaton, J., Kortum, S., 2001. Trade in capital goods. Eur. Econ. Rev. 45(7), 1195-1235.

Edquist, C., Hommen, L., McKelvey, M., 2001. Innovation and Employment: Process versus Product Innovation. Edward Elgar, Cheltenham.

Efrat, K., 2014. The direct and indirect impact of culture on innovation. Technovation 34(1), 12-20.

Eichengreen, B., Irwin, D.A., 1998. The regionalisation of the world economy. In: Frankel, J.A. (Ed.), The Role of History in Bilateral Trade Flows. University of Chicago Press, Chicago, pp. 33-57.

Frankel, J., Romer, D., 1999. Does trade cause growth? Am. Econ. Rev. 89(3), 379-399.

Freeman, C., 1987. National systems of innovation: the case of Japan. Technology Policy and Economic Performancek. Printer Publishers, Londonk.

Friedman, T.L., 2005. The World Is Flat: A Brief History of the Twenty-First Century. Farrar, Straus, and Giroux, New York.

Gagliardi, L., 2015. Does skilled migration foster innovative performance? Evidence from british local areas. Reg. Stud. 94(4), 773-794.

Ganguli, I., 2015. Immigration and ideas: what did Russian scientists "bring" to the United States? J. Labor Econ. 33(S1 Part 2), S257-288.

Glaeser, E., J.A. Scheinkman, J., Shleifer, A., 1995. Economic growth in a cross-section of cities. J. Monet. Econ. 36(1), 117-143.

Goldstein, H., Renault, C., 2004. Contributions of universities to regional economic development: a quasi-experimental approach. Reg. Stud. 38(7), 733-746.

Greene, W.H., 1994. Accounting for Excess Zeros and Sample Selection in Poisson and Negative Binomial Regression Models. NYU Working Paper No. EC-94-10

Griffith, R., Macartney, G., 2014. Employment protection legislation, multinational firms, and innovation. Rev. Econ. Stat. 96(1), 135-150.

Griliches, Z., 1992. The search for R\&D spillovers. Scand. J. Econ. 94(0), S29-47.

Grogger, J., Hanson, G., 2011. Income maximization and the selection and sorting of international migrants. J. Dev. Econ. 95(1), 42-57.

Grossman, G., Helpman, E., 1991. Innovation and Growth in the Global Economy. MIT Press, Massachusetts, USA.

Guellec, D., van Pottelsberghe de la Potterie, B., 2004. From R\&D to productivity growth: do the institutional settings and the source of funds of R\&D matter? Oxf. Bull. Econ. Stat. 66(3), 353-378.

Hall, B.H., Jaffe, A.B., Trajtenberg, M., 2001. The NBER Patents Citations Data File: Lessons, Insights and Methodological Tools. National Bureau of Economic Research Working Paper No. 8498
Hall, B.H., Jaffe, A.B., Trajtenberg, M., 2005. Market value and patent citations. RAND J. Econ. 36(1), 16-38.

Hausman, J.A., Hall, B., Griliches, Z., 1984. Econometric Models for Count Data with an Application to the Patents-R\&D Relationship. NBER Working Paper No. 0017

Helpman, E., Melitz, M., Rubinstein, Y., 2008. Estimating trade flows: trading partners and trading volumes. Quart. J. Econ. 123(2), 441-487.

Herbig, P., Dunphy, S., 1998. Culture and innovation. Cross Cult. Manag. 5(4), 13-21.

Hofstede, G., 1980. Culture's Consequences: International Differences in Work-Related Values. Sage Publications, Beverly Hills CA.

Hofstede, G., 2001. Culture's Consequences: Comparing Values, Behaviors, Institutions and Organizations Across Nations, 2nd edition. Sage Publications, Thousand Oaks CA.

Howells, J., 1999. Regional systems of innovation. Innov. Policy Glob. Econ. 67-93.

Hsu, P.-H., Tian, X., Xu, Y., 2014. Financial development and innovation: cross-country evidence. J. Financ. Econ. 112(1), 116-135.

Hunt, J., Gauthier-Loiselle, M., 2010. How much does immigration boost innovation? Am. Econ. J. 2(2), 31-56.

Jaffe, A.B., 1986. Technological opportunity and spillovers of R\&D: evidence from firms' patents, profits, and market value. Am. Econ. Rev. 76(5), 984-1001.

Jaffe, A.B., Trajtenberg, M., Henderson, R., 1993. Geographic localization of knowledge spillovers as evidenced by patent citations. Quart. J. Econ. 108(3), 577-598.

Jones, G.K., Davis, H., 2000. National culture and innovation: implications for locating global R\&D operations. Manag. Int. Rev. 40(1), 11-39.

Keller, W., 2002. Trade and the transmission of technology. J.Econ. Growth 7(1), 5-24.

Keller, W., Yeaple, S.R., 2009. Multinational enterprises, international trade, and productivity growth: firm-level evidence from the United States. Rev. Econ. Stat. 91(4), 821-831.

Kerr, S., Kerr, W., Özden, C., Parsons, C., 2016. Global talent flows. J. Econ. Perspect. $30(4), 8306$

Kerr, W., 2008. Ethnic scientific communities and international technology diffusion. Rev. Econ. Stat. 90(3), 518-537.

Kerr, W.R., Lincoln, W.F., 2010. The supply side of innovation: H-1b visa reforms and us ethnic invention. J. Labor Econ. 28(3), 473-508.

Lambert, D., 1992. Zero-inflated poisson regression, with an application to defects in manufacturing. Technometrics 34(1), 1-14.

Levine, R., 2004. Finance and Growth: Theory and Evidence. NBER Working Paper No. 10766

Licht, A., Siegel, J., 2006. The social dimensions of entrepreneurship. In: Casson, M., Yeung, B. (Eds.), Oxford Handbook of Entrepreneurship. Oxford University Press, Oxford.

Lucas, R., 1988. On the mechanics of economic development. J. Monet. Econ. 22(1), $3-42$.

Lucas, R.E., 2009. Ideas and growth. Economica 76(301), 1-19.

Lundvall, B.-å., 1998. Why study national systems and national styles of innovation? Technol. Anal. Strategic Manag. 10 (4), 403-422.

Maggioni, M.A., Uberti, T., 2009. Knowledge networks across europe: which distance matters? Ann. Reg. Sci. 43(3), 691-720.

Mancusi, M.L., 2008. International spillovers and absorptive capacity: across-country cross-sector analysis based on patents and citations. J. Int. Econ. 76(2), 155-165.

Martinez-Roman, J.A., Gamero, J., Tamayo, J.A., 2011. Analysis of innovation in SMEs using an innovative capability-based non-linear model: a study in the province of seville (spain). Technovation 31 (9), 459-475.

Mayda, A., 2010. International migration: a panel data analysis of the determinants of bilateral flows. J. Popul. Econ. 23(4), 1249-1274.

Mayer, T., Zignago, S., 2011. Notes on CEPII's Distances Measures: The Geodist Database. CEPII Research Center No. 2011 -25

McCallum, J., 1995. National borders matter: Canada-U.S. regional trade patterns. Am. Econ. Rev. 85(3), 615-623.

McCann, P., 2008. Globalization and economic geography: the world is curved, not flat. J. Reg. Eco. Soc. 1(3), 351-370.

McFadden, D., 1974. The measurement of urban travel demand. J Public Econ 3(4), 303-328.

Miguélez, E., 2016. Inventor diasporas and the internationalization of technology. World Bank Economic Review 1-28. https://doi.org/10.1093/wber/lhw013). (in press)

Miguélez, E., Fink, C., 2013. Measuring the International Mobility of Inventors: A New Database. WIPO Economics \& Statistics Series, Working Paper No. 8

Miguélez, E., Moreno, R., 2013. Research networks and inventors' mobility as drivers of innovation: evidence from Europe. Reg. Stud. 47(10), 1668-1685.

Miguélez, E., Moreno, R., 2013. Skilled labour mobility, networks and knowledge creation in regions: a panel data approach. Ann. Reg. Sci. 51(1), 191-212.

Miguélez, E., Moreno, R., 2014. What attracts knowledge workers? The role of space, social networks. J. Reg. Sci. 54(1), 33-60.

Miguélez, E., Moreno, R., Surinach, J., 2010. Inventors on the move: tracing inventors' mobility and its spatial distribution. Pap. Reg. Sci. 89(2), 251-274.

De la Mothe, J., Paquet, G., 2012. Local and Regional Systems of Innovation. Vol. 14 Springer Science \& Business Media.

OECD, 2004. Science and Technology Indicator Scoreboard.

Ortega, F., Peri, G., 2013. The effect of income and immigration policies on international migration. Migr. Stud. 1(1), 47-74.

Pakes, A., Griliches, Z., 1980. Patents and R\&D at the firm level: a first report. Econ. Lett. 5(4), 377-381.

Papademetriou, D.G., Sumption, M., 2013. Attracting and Selecting from the Global Talent Pool-Policy Challenges. Migration Policy Institute, Washington DC.

Peri, G., 2005. Determinants of knowledge flows and their effect on innovation. Rev. Econ. Stat. 87(2), 308-322.

Perugini, C., Signorelli, M., 2010. Youth labour market performance in European regions. 
Econ. Change Restruct. 43(2), 151-185.

Philippidis, G., Resano?Ezcaray, H., Sanjuán-López, A.I., 2013. Capturing zero?trade values in gravity equations of trade: an analysis of protectionism in agro-food sectors. Agricult. Econ. 44(2), 141-159.

Ravenstein, E.G., 1889. The laws of migration. J. R. Stat. Soc. 52(2), 241-305.

Redding, S., 1996. The low-skill, low-quality trap: strategic complementarities between human capital and R\&D. Econ. J. 106 (435), 458-470.

Rivera-Batiz, L., Romer, P., 1991. Economic integration and endogenous growth. Quart. J. Econ. 106(2), 227-244.

Rodríguez-Pose, A., Cataldo, M.D., 2014. Quality of government and innovative performance in the regions of Europe. J. Econ. Geogr. 15(4), 673-706.

Rodríguez-Pose, A., Crescenzi, R., 2008. Mountains in a flat world: why proximity still matters for the location of economic activity. Camb. J. Reg. Econ. Soc. 1(3), 371-388.

Romer, P.M., 1986. Increasing returns and long-run growth. J. Polit. Econ. 94(5), 1000-1037.

Romer, P.M., 1989. Human Capital and Growth: Theory and Evidence. National Bureau of Economic Research Working Paper Series No. 3173

Romer, P.M., 1990. Endogeneous technological change. J. Polit. Econ. 98(5), S71-102.

Roper, S., Love, J.H., Bonner, K., 2017. Firms' knowledge search and local knowledge externalities in innovation performance. Research Policy 46 (1), 43-56.

Soskice, D., 1997. German technology policy, innovation and national institutional frameworks. Ind. Innov. 4(1), 75-96.

Strand, Ø., Leydesdorff, L., 2013. Where is synergy indicated in the norwegian innovation system? Triple-helix relations among technology, organization, and geography. Technol. Forecast. Soc. Change 80 (3), 471-484.

Thompson, P., 2006. Patent citations and the geography of knowledge spillovers: evidence from inventor- and examiner-added citations. Rev. Econ. Stat. 88(2), 383-388.

Tinbergen, J., 1962. Shaping the World Economy: Suggestions for an International Economic Policy. The Twentieth Century Fund, New York.

UN-DESA, OECD, 2013. World Migration in Figures.

Veugelers, R., Rey, E.D., 2014. The Contribution of Universities to Innovation, (Regional) Growth and Employment. European Expert Network on Economics of Education (EENEE) Analytical Report No. 18

Vuong, Q.H., 1989. Likelihood ratio tests for model selection and non-nested hypothesis. Econometrica 57(2), 307-333.

Wolf, H.C., 2000. Intra-national home bias in trade. Rev. Econ. Stat. 82(4), 555-563.

Wooldridge, J.M., 2002. Econometric Analysis of Cross Section and Panel Data. MIT Press, Cambridge.

Xiong, B., Beghin, J., 2011. Does European aflatoxin regulation hurt groundnut exporters from Africa? Eur. Rev. Agric. Econ. 39(4), 589-609.

Young, A., 1991. Learning by doing and the dynamic effects of international trade. J. Econ. 106(2), 369-405.
Zhao, S., Cacciolatti, L., Lee, S.H., Song, W., 2015. Regional collaborations and in digenous innovation capabilities in china: a multivariate method for the analysis of regional innovation systems. Technol. Forecast. Soc. Change 94, 202-220.

Kyriakos Drivas is an Assistant Professor at the Department of Economics of the University of Piraeus, Greece. He has received his PhD from University of CaliforniaBerkeley, Department of Agricultural and Resource Economics. He has worked as an adjunct lecturer at Hellenic Open University, a post-doctoral researcher at the Agricultural University of Athens, the Athens University of Economics and Business and the Agriculture Economics Research Institute. He has also worked as a visiting economist at the United States Patent and Trademark Office and external research associate at the Hellenic Industrial Property Organization. His research interests lie on the empirical study of innovation management, intellectual property rights, economic growth and technology transfer.

Claire Economidou is Professor at the Department of Economics of the University of Piraeus, Greece. She holds a Ph.D. in Economics from the University of WisconsinMilwaukee (2004), and her research interests lie on the fields of Economic Growth and Economics of Innovation. More specifically, her current research agenda is mainly concentrated on the knowledge diffusion dynamics and its impact on local innovation and growth perspectives, the role of financial frictions on country's innovation performance, the assessment of the private value of patents, the role of institutions and social capital in shaping entrepreneurship and innovation, among others.

Dimitrios Karamanis is a Post-Doc researcher at the Department of Economics at the University of Piraeus, Greece. He holds a M.Sc. of Healthcare Management from Hellenic Open University, a M.Sc. in Data Science from Athens University of Economics and Business, and a B.A. of Economics from Aristotle University of Thessaloniki, Greece. His research interests lie on the areas of Innovation, Entrepreneurship, and Skilled Migration mobility. His research has been financed from a number of prestigious national and European grants.

Mark Sanders is an Associate Professor at Utrecht School, of Economics, Utrecht University, the Netherlands. He researches and teaches topics that connect entrepreneurship, innovation and the transition towards more sustainable economic growth. His methods are both empirical and theoretical and his teaching is both within the economics department and in courses at the faculty of geosciences and sciences. Mark is also a member of the Sustainable Finance Lab that aims to make financial markets contribute to this transition. 